\title{
Inflammation Effects on Motivation and Motor Activity: Role of Dopamine
}

\author{
Jennifer C Felger ${ }^{\star, 1,2}$ and Michael T Treadway ${ }^{1,2,3}$ \\ ${ }^{1}$ Department of Psychiatry and Behavioral Sciences, Emory University School of Medicine, Atlanta, GA, USA; ${ }^{2}$ Winship Cancer \\ Institute, Emory University, Atlanta, GA, USA; ${ }^{3}$ Department of Psychology, Emory University, Atlanta, GA, USA
}

Motivational and motor deficits are common in patients with depression and other psychiatric disorders, and are related to symptoms of anhedonia and motor retardation. These deficits in motivation and motor function are associated with alterations in corticostriatal neurocircuitry, which may reflect abnormalities in mesolimbic and mesostriatal dopamine (DA). One pathophysiologic pathway that may drive changes in DAergic corticostriatal circuitry is inflammation. Biomarkers of inflammation such as inflammatory cytokines and acute-phase proteins are reliably elevated in a significant proportion of psychiatric patients. A variety of inflammatory stimuli have been found to preferentially target basal ganglia function to lead to impaired motivation and motor activity. Findings have included inflammation-associated reductions in ventral striatal neural responses to reward anticipation, decreased DA and DA metabolites in cerebrospinal fluid, and decreased availability, and release of striatal DA, all of which correlated with symptoms of reduced motivation and/or motor retardation. Importantly, inflammation-associated symptoms are often difficult to treat, and evidence suggests that inflammation may decrease DA synthesis and availability, thus circumventing the efficacy of standard pharmacotherapies. This review will highlight the impact of administration of inflammatory stimuli on the brain in relation to motivation and motor function. Recent data demonstrating similar relationships between increased inflammation and altered DAergic corticostriatal circuitry and behavior in patients with major depressive disorder will also be presented. Finally, we will discuss the mechanisms by which inflammation affects DA neurotransmission and relevance to novel therapeutic strategies to treat reduced motivation and motor symptoms in patients with high inflammation.

Neuropsychopharmacology Reviews (2017) 42, 216-24I; doi:10.1038/npp.2016.143; published online 24 August 2016

\section{INTRODUCTION}

Deficits in aspects of reward processing, motivation, and motor function are common in neuropsychiatric disorders, particularly in patients with major depressive disorder (MDD), bipolar disorder, and schizophrenia (Caligiuri and Ellwanger, 2000; Morrens et al, 2007; Pizzagalli, 2014; Treadway and Zald, 2011). These symptoms have been associated with abnormal sensitivity to reinforcement during learning or decision-making and concomitant alterations in dopaminergic corticostriatal circuitry (Hamilton et al, 2011; Kaiser et al, 2015; Treadway and Pizzagalli, 2014). These findings imply acute dysfunction within mesolimbic dopamine (DA) pathways, although the cause of such alterations is unclear.

One candidate mechanism is inflammation. A significant proportion of patients with psychiatric disorders exhibit a

${ }^{*}$ Correspondence: $\mathrm{Dr}$ JC Felger, Winship Cancer Institute, Emory University School of Medicine, 1365 Clifton Road, Clinic B 5103, Atlanta, GA 30322, USA, Tel: 404-727-3987, Fax: 404-778-3965,

E-mail: jfelger@gmail.com

Received 7 May 2016; revised 13 July 2016; accepted 27 July 2016; accepted article preview online 2 August 2016 chronic, low-grade inflammation, as measured by increased peripheral and central inflammatory cytokines, inflammatory mediators, and acute-phase reactants (for review, see Barbosa et al, 2014, Felger and Lotrich, 2013b, Goldsmith et al, 2016b and Haroon et al, 2012). Findings from numerous laboratories have consistently indicated that innate immune activation and the release of inflammatory cytokines preferentially affect reward circuitry and basal ganglia DA to contribute to reduced motivation and motor slowing (Brydon et al, 2008; Capuron et al, 2007; Capuron et al, 2012; Eisenberger et al, 2010; Felger and Miller, 2012; Harrison et al, 2015b; Majer et al, 2008). In humans, this evidence stems primarily from studies in healthy volunteers acutely administered cytokine inducers such as endotoxin or typhoid vaccination (Eisenberger et al, 2010; Harrison et al, 2015b), and from patients chronically administered inflammatory cytokines (eg, interferon (IFN)- $\alpha$ ) as therapy for some cancers and infectious diseases (Capuron et al, 2007; Capuron et al, 2012). Preclinical data in non-human primates and rodents also suggest that the effects of inflammation on reward circuitry and motivation are mediated by cytokine-induced reductions in striatal DA (Felger et al, 2013c; Kitagami et al, 2003; Nunes et al, 2014). 
Symptoms related to reduced motivation and motor slowing are notoriously difficult to treat in patients with psychiatric disorders and in patients administered chronic IFN- $\alpha$ (Capuron et al, 2002a; Morrow et al, 2003; Raison et al, 2005b; Shelton and Tomarken, 2001). Furthermore, a relationship exists between high levels of inflammation and treatment resistance, particularly in depression (Cattaneo et al, 2013; Lanquillon et al, 2000; Raison et al, 2013a; Sluzewska et al, 1997). Moreover, symptoms of anhedonia and motor slowing are difficult to treat with selective serotonin reuptake inhibitors (SSRIs; Dunlop and Nemeroff, 2007; Rush, 2007; Targum and Fava, 2011; Trivedi et al, 2008), suggesting that other neurotransmitter systems, such as DA, may be involved in SSRI-resistant, inflammation-related symptoms (Nutt et al, 2007). Nevertheless, classical stimulant medications that increase DA release and/or block DA reuptake have demonstrated limited long-term efficacy in the treatment of fatigue in patients with inflammation-associated medical illnesses (Butler et al, 2007; Mar Fan et al, 2008; Moraska et al, 2010). Therefore, a better understanding of the mechanisms by which inflammation and cytokines may affect DA function will inform strategies to improve the treatment of symptoms related to reduced motivation and motor slowing in medically ill and medically healthy individuals.

This review will highlight the wealth of clinical and translational work demonstrating the impact of peripheral inflammation on DA, corticostriatal circuitry, motivation, and motor function following acute or chronic administration of cytokines or inflammatory stimuli. Furthermore, studies involving administration of inflammatory stimuli have informed recent work in patients with MDD, which has revealed similar relationships between increased peripheral cytokines and other inflammatory markers, alterations in DA-relevant neurocircuitry, motivational deficits, and psychomotor slowing (Felger et al, 2016; Goldsmith et al, 2016a). Although many aspects of reward-related behaviors, such as reinforcement learning, have only begun to be explored in relation to increased inflammation, these concepts may be relevant to future studies examining relationships between DA and motivated behavior in the context of increased inflammation, and are reviewed in the context of health and psychiatric illness. Mechanisms by which inflammation may affect DA and corticostriatal circuitry, as well as implications for the treatment of inflammation-related behavioral symptoms, are also discussed.

\section{NORMAL AND ABNORMAL DA FUNCTION IN THE CONTEXT OF MOTIVATION AND PSYCHOMOTOR FUNCTION}

\section{Striatal DA, Motivation, and the Value of Action}

DA's basic roles in approach-related behavior, including effort expenditure (Correa et al, 2002), reinforcement learning (Schultz, 2015), and motor control (Bernheimer et al, 1973; Romo and Schultz, 1990), have been thoroughly covered in the literature and will only be briefly reviewed here. Initial evidence for these functions occurred primarily through electrophysiological techniques of DA cell activity, DAergic lesions, and pharmacological manipulations at DAergic terminal field regions. This body of work has led to several widely accepted principles regarding DA's various functions. These include the idea that nigrostriatal DA neurons projecting to dorsal striatum and ventrolateral putamen are principally engaged in motor control (Guo et al, 2014; Puryear et al, 2010), whereas DA neurons within the ventral tegmental area (VTA) projecting to ventral striatum are primarily involved in reward processing. Within the VTA, it has further been suggested that phasic DA is responsible for encoding reward prediction errors (RPEs) capable of driving reward-related reinforcement learning (Schultz, 2002) via receptor subtype-dependent potentiation or depression within 'go' and 'no-go' pathways in the striatum (Frank and O'Reilly, 2006; Frank et al, 2004; Reynolds et al, 2001). In contrast, tonic DA in the striatum has been hypothesized to have a key role in motivation (including aversive motivation; Salamone and Correa, 2012; Salamone et al, 1997), effort (Correa et al, 2002), and response vigor (Niv et al, 2007; Phillips et al, 2007). In the case of DA's role in effort expenditure, a large number of studies have demonstrated that local blockade of DA signaling through either 6-hydroxy DA lesions (Salamone et al, 2001) or vesicular monoamine transport inhibition (Nunes et al, 2013) can shift an animal's preference away from preferred rewards requiring greater effort.

It is also worth highlighting the now well-established distinction between manipulations of DA on processes related to reinforcement learning and motivation as compared with hedonic reactions. As has been well documented elsewhere, DA modulation appears to selectively influence various forms of approach-related behavior in the context of reward and reward-predicting cues, whereas having little effect on hedonic reactions to reward receipt (for reviews, see Berridge, 2007 and Berridge and Kringelbach, 2013). Further, the near total absence of DA does not ablate the expression of putatively hedonic preferences, such as sucrose preference (Cannon and Palmiter, 2003), provided that behavioral effort is minimal (Salamone et al, 2001).

Human neuroimaging and pharmacological studies have largely corroborated this preclinical literature, with clear evidence that BOLD signal within both the DAergic midbrain (D'Ardenne et al, 2008) and ventral striatal terminal field regions (O'Doherty et al, 2004; Schönberg et al, 2007) exhibit fluctuations in response to rewarding outcomes consistent with RPE models, and meet necessary axiomatic requirements of a true RPE signal (Rutledge et al, 2010) that can be modulated by DAergic agents (Pessiglione et al, 2006). Also in keeping with animal studies, effort expenditure for rewards can be increased or decreased through either potentiation (Wardle et al, 2011) or attenuation (Venugopalan et al, 2011) of DA levels, and individual 
differences in striatal DA release predict effort-related preferences (Treadway et al, 2012b).

Human studies also support an absence of DAergic effects on hedonic responses (Berridge and Kringelbach, 2008). Despite early results suggesting that DA-acting drugs such as amphetamine and cocaine could induce euphoric mood states (de Wit et al, 1986), and that such euphoria was correlated with amphetamine-induced DA release in the striatum (Drevets et al, 2001), further data suggested that these effects may result from DA stimulation of opioid-rich 'hedonic hotspots'. For example, when amphetamine is taken in conjunction with an opioid antagonist, euphoria is significantly diminished (Jayaram-Lindstrom et al, 2004). In contrast, subtler augmentations of DA, such as L-3,4dihydroxyphenylalanine (L-DOPA) administration, show no effect on hedonic response, despite clear modulation of motivation and response vigor (Beierholm et al, 2013; Liggins et al, 2012; Sharot et al, 2012; Sharot et al, 2009). Further, transient reduction of DA increased subjective reports of boredom and apathy, with no effect on affective ratings (McLean et al, 2004; Venugopalan et al, 2011).

Within the past 10 years, however, new discoveries have revealed some unexpected complexities to these traditional boundaries. First, there is clear evidence from both human and primate electrophysiological studies that nigrostriatal DA neurons also exhibit many of the phasic RPE-type signals previously believed to exist primarily within the ventral striatum (Varazzani et al, 2015; Zaghloul et al, 2009), blurring the line between DA's putatively distinct roles in movement and reward. Conversely, whereas nigrostriatal DA projections are thought to primarily regulate motor function, electrophysiologic, and optogenetic studies have revealed that DAergic neurons in the VTA may also contribute to initiation of locomotor activity (Guo et al, 2014; Puryear et al, 2010), which may reflect motivational aspects of motor output. In addition, the discovery of heterogeneous populations of DA neurons within the VTA that selectively respond to either rewards or punishments and project either to ventral striatum or medial prefrontal cortex (mPFC), respectively, raises questions about the long-held view that DA neurons' primary response to negative outcomes was limited to transient 'dips' in firing (Lammel et al, 2011; Lammel et al, 2012). Even more strikingly, optogenetic induction of phasic burst firing in DA cells that project to nucleus accumbens (NAcc) during stress produced a depressive phenotype in mice, whereas the same stimulation applied to VTA DA neurons projecting to MPFC had no effect (Chaudhury et al, 2013), further highlighting the functional importance of these heterogeneous DA populations.

Using fast-scan voltammetry in the striatum, one critical study in recent years isolated a new 'ramping' DA signal associated with active goal pursuit (Howe et al, 2013). The slope of these DAergic 'ramps' appeared to encode activitydependent proximity to a goal and seemed to confound the classic phasic/tonic dichotomy. Even more recently, a study combining reinforcement learning with both go and no-go responses found that the strength of DAergic RPE signaling in the striatum was heavily moderated by whether go or nogo responses were required to harvest a reward following a reward-predicting cue (Syed et al, 2016). Expanding on these results, Hamid et al (2016) used extended analysis of striatal DA release over repeated trials to show that DA ramps encoded an expected value of action, whereas short-term phasic bursts and dips reflected prediction error updates to these expected value estimates (Collins and Frank, 2016).

Taken together, these exciting new results further refine our understanding of DA's role in approach-related behavior as well as the implications of disruptions within DA-related circuitry. Specifically, they suggest that alterations to striatal DAergic tone as well as inappropriate firing patterns may have diverse contradictory effects on motivational states, reinforcement learning, and movement. This broad array of consequences to DAergic alterations may contribute to the challenge in identifying stable deficits both across and within clinical diagnostic groups. Indeed, one of the potential advantages of focusing on motivational impairments in the context of inflammation-DA interactions is that it may point to a more precise phenotype with greater homogeneity at the level of pathophysiology.

\section{Reduced Motivation and Psychomotor Function in Psychiatric Disorders-Behavioral Evidence and Clinical Correlates}

As the preclinical literature has progressively refined our understanding of the specific behaviors and information processing that is affected by DA signaling, clinical researchers have been increasingly challenged to establish more precise measure of reward-related symptoms. In the diagnosis of MDD, for example, loss of interest, decreased sexual drive, fatigue, and psychomotor slowing have been viewed as distinct depressive symptoms (Feighner et al, 1972), whereas the single criterion of anhedonia has been defined so broadly that it can be met through demonstrated 'loss of pleasure or interest' (italics added) in previously enjoyed activities. This lumping of pleasure and interest/ motivation echo the distinction between 'wanting' and 'liking' aspects of reward behavior, as it pertained to DA function, and is just one example of how current diagnostic criteria may be out of step with neurobiological reality (Treadway and Zald, 2011; Treadway and Zald, 2013). Similarly, the putatively distinct symptoms of reduced motivation, fatigue, and psychomotor slowing in depression may share a common mechanism in terms of inflammation effects on DA availability (as argued in the sections 'Inflammation-induced impairments in motivation and motor activity-links to striatal dopamine function' and 'Mechanisms of inflammation effects on dopamine synthesis and release' below)-at least for a subset of depressed patients (Raison and Miller, 2011).

In seeking to refine the assessment of reward-related deficits in psychiatric disorders, a number of self-report and behavioral measures have been developed in recent years that 
attempt to isolate or dissociate various subconstructs of reward. This includes behavioral measures of effort expenditure (Gold et al, 2013; Hartmann et al, 2015; Hershenberg et al, 2016; Treadway et al, 2009; Wolf et al, 2014), affective responses to positive stimuli (Bylsma et al, 2008; Dichter et al, 2010; Gold et al, 2008), and reinforcement learning (Pizzagalli et al, 2008) as well as self-report measures that seek to dissociate aspects of anticipation, motivation and enjoyment (eg, Cooper et al, 2008; Gard et al, 2006).

Armed with these purer measures, researchers have begun to clarify the nature of reward-related deficits in psychopathology as well as evidence for DA involvement. In unipolar depression, several studies have found evidence for reduced physical effort expenditure in exchange for monetary rewards (Hershenberg et al, 2016; Treadway et al, 2012a; Yang et al, 2014). In a related effort paradigm using a handgrip apparatus, Clery-Melin et al (2011) observed that patients exerted less physical force than controls and were less responsive to monetary incentives. Within these patient samples, relationship between reported anhedonic symptoms and effortful performance has been mixed. Several studies have reported expected negative associations between effortful responses and anhedonic symptoms (Hershenberg et al, 2016; Treadway et al, 2012a; Yang et al, 2014), yet in several instances there was either no observed relationship (CleryMelin et al, 2011) or a an unexpected positive relationship between effort and total BDI scores (Treadway et al, 2012a), although further analysis suggests this might be driven by a positive association between self-criticism end effortful performance (Hershenberg et al, 2016). Of these studies, only one study to date has also examined effort-related behavior in patients diagnosed with bipolar disorder (currently depressed), and observed a near identical pattern when compared with unipolar patients (Hershenberg et al, 2016).

In schizophrenia, an even greater number of studies have found evidence for effort-related abnormalities using a variety of effort-tasks (Barch et al, 2014; Fervaha et al, 2013; Gold et al, 2013; Hartmann et al, 2015; McCarthy et al, 2016; Reddy et al, 2015; Strauss et al, 2016). Interestingly, although some studies have detected an overall decrease in effort expenditure (Hartmann et al, 2015; McCarthy et al, 2016; Wolf et al, 2014), the most consistent group differences observed across studies have implicated deficits in effort allocation rather than effort expenditure (Barch et al, 2014; Gold et al, 2013; Horan et al, 2015; Reddy et al, 2015). That is, schizophrenia patients may not choose to expend less effort overall, but they appear to be significantly less sensitive to reward-related information when choosing when to expend effort. Although the precise role for DAergic alterations in these effort allocation deficits remains unknown, the aberrant salience model (Winton-Brown et al, 2014) would predict that failure of DA neurons to response appropriately to reward-predicting cues could result in sub-optimal effort allocation.

As with depression, the associations between performance on effort-related measures and measures of negative symptoms in schizophrenia have been mixed. Several studies reported relationships with between reduced effort and negative symptoms (Hartmann et al, 2015; Strauss et al, 2016; Wolf et al, 2014), whereas others found that the strongest relationships were between measures of poor effort allocation and negative symptoms (Barch et al, 2014; Reddy et al, 2015). Still other studies found that greater negative symptoms severity as assessed by clinical interview measures such as the Clinical Assessment Interview for Negative Systems (CAINS; Kring et al, 2013) was associated with greater effort expenditure (McCarthy et al, 2016). Although the causes of this discrepancy are not entirely clear, one possibility suggested by Strauss and Gold is that schizophrenia patients are often limited in their ability to accurately report on and forecast their motivational states (Strauss and Gold, 2012). This hypothesis has found recent support using ecological-momentary assessment (EMA) methods. One study found that patients reported engaging in significantly fewer effortful daily activities, despite reporting greater anticipation (Gard et al, 2014). Even more striking, a second study found that effort performance during a laboratory task was predictive of negative symptoms as assessed by EMA, but neither was correlated with negative symptoms as measured by the CAINS (Erin Moran, personal communication).

In addition to deficits in motivation, psychomotor slowing is a prominent feature of both mood disorders and schizophrenia, and has been shown to correlate with symptoms of anhedonia and amotivation (Heinz et al, 1998; Lemke et al, 1999; Stein, 2008). Motor retardation can be assessed in psychiatric patients using objective measures of psychomotor processing or reaction time and tests of fine motor speed, which have been shown to be more sensitive than self-reported symptoms and clinician ratings (Bennabi et al, 2013; Caligiuri and Ellwanger, 2000; Morrens et al, 2007). In schizophrenia, psychomotor symptoms have been shown to correlate with negative symptoms, such as apathy and amotivation, as well as with depressive symptoms, and confer significant impairments in function and increased patient burden (Ananth et al, 1991; Heinz et al, 1998; Morrens et al, 2007). Motor deficits are also observed in patients with bipolar II, as well as in bipolar I during the depressed phase (Bennabi et al, 2013; Mitchell et al, 2001). Interestingly, objective measures of motor function have revealed different patterns of motor deficits in patients with unipolar depression versus bipolar II disorder. Bipolar patients showed greater impairment in scaling of movement velocity in anticipation of changing target distances (similar to bradykinesia seen in patients with Parkinson's disease (PD)) and patients with unipolar depression primarily exhibited deficits in tests of psychomotor processing speed that probe more cognitive aspects of motor function (eg, digit symbol substitution and trail making tests; Caligiuri and Ellwanger, 2000). Indeed, differential performance on these tests classified unipolar and bipolar depression with a high degree of accuracy (Caligiuri and Ellwanger, 2000). Moreover, greater severity of motor impairments has been 
associated with increased depression severity and with treatment outcomes (Bennabi et al, 2013; Caligiuri and Ellwanger, 2000). Although findings have been mixed due to differences in the definition and measurement of psychomotor symptoms, as well as the use of different drugs and variable doses within a class, evidence suggests that agents with broad pharmacologic actions (eg, tricyclics, combined serotonin-norepinephrine or norepinephrine-DA reuptake inhibitors) may be more efficacious in the treatment of psychomotor retardation than SSRIs (Buyukdura et al, 2011; Parker et al, 2010). Finally, patients with severe depression and psychomotor retardation are at increased risk for the development of neurological disorders such as PD (Leentjens et al, 2003; Walter et al, 2015), which is also thought to involve inflammation effects on DA neurons (Lotharius et al, 2005). Therefore, objective measures of psychomotor slowing may serve as excellent behavioral markers for the effects of inflammation on corticostriatal circuitry and DA in patients with psychiatric illness.

\section{Reduced Motivation and Psychomotor Function in Psychiatric Disorders-Links to Striatal DA Function}

Given robust evidence that striatal DA is necessary to overcome effortful response costs, combined with repeated observations of altered motivation and psychomotor behavior in psychiatric patients with anhedonia, a growing body of work has sought to link these symptoms to alterations in DAergic circuitry. These studies have included pharmacological probes to enhance or reduce DA availability, behavioral paradigms believed to engage DAergic activity or neurochemical measures of DA-related proteins.

In the case of functional imaging, early functional magnetic resonance imaging (fMRI; and non-imaging) studies frequently focused on passive consumption of positive stimuli (eg, see Keedwell et al, 2005, Mitterschiffthaler et al, 2003 and Surguladze et al, 2005). These studies observed altered neural responses primarily in $\mathrm{mPFC}$, an area believed to support encoding of the hedonic impact of rewarding stimuli (Berridge and Kringelbach, 2013; Hare et al, 2008). As researchers began to focus more specifically on DAergic mechanisms, an increasing number of functional imaging studies have turned to paradigms that assess striatal responses to rewardpredicting cues or reward feedback, both of which have been linked to striatal DA (Ferenczi et al, 2016; Knutson and Gibbs, 2007). These latter approaches have been mostly consistent in their observation of blunted striatal responses to reward outcomes or reward-predicting cues in MDD patients (Dichter et al, 2009; Forbes et al, 2009; Gotlib et al, 2010; Pizzagalli et al, 2009), and these initial findings have been replicated in recent studies with larger patient samples. Indeed, one recent study of over 1500 adolescents found that reduced ventral striatal activity during reward anticipation was associated with clinical or subclinical depression, and that lower ventral striatal activity in non-depressed teens at the time of scanning was predictive of developing depressive symptoms over a 2-year follow-up period (Stringaris et al, 2015). In addition to neural responses to anticipation, a second recent study identified a failure in the expected temporal shift of striatal responses to reward cues from reward outcomes as a task was learned, a pattern that was specific to patients with greater anhedonia (Greenberg et al, 2015).

In schizophrenia, even greater evidence exists for altered striatal signaling during reward anticipation and RPEs. To date, the most reliable decreases in ventral striatal activity have been observed during periods of reward anticipation (for a recent meta-analysis, see Radua et al, 2015), which have also been linked to reduced effortful behavior in schizophrenia (Wolf et al, 2014). In addition, recent work has demonstrated both a blunting of neural prediction errors to contextually relevant cues (Morris et al, 2011) as well as behavioral evidence for enhanced prediction error learning for irrelevant stimuli (Hannestad et al, 2012b; Williams et al, 2013). These findings are consistent with predictions from the aberrant salience hypothesis, which predicts that both positive and negative symptoms are linked to irregular striatal DA systems that may fail to appropriately respond to meaningful reward incentives (Winton-Brown et al, 2014). Interestingly, transdiagnostic studies comparing groups of patients with schizophrenia and depression have found similar decreases relative to controls for both reward anticipation (Arrondo et al, 2015) and prediction error signaling (Gradin et al, 2011), with little evidence of clear differences between patient groups.

As a global measure of neural activity, fMRI studies demonstrating alterations of striatal activity can provide only circumstantial evidence for DAergic impairment. Studies combining functional imaging with pharmacological manipulations of DA systems can therefore provide further support for the role of DA in observed group differences. Hasler and colleagues used $\alpha$-para-methyl-tyrosine to temporarily deplete DA in patients with current MDD, and found that this produced a significant increase in glucose consumption in ventral striatum (Hasler et al, 2008). Further implicating some form of DAergic depletion in depression is the observation that depressed patients experience a much stronger affective response to amphetamine than controls (Tremblay et al, 2002; Tremblay et al, 2005), which is known to be linked to the magnitude of striatal DA release (Drevets et al, 2001). Of relevance to schizophrenia, a recent study tested the effects of methamphetamine administration on RPE signals in healthy controls and found that amphetamine significantly disrupted striatal prediction error encoding, consistent with a role for DA in prediction error abnormalities observed in schizophrenic patients (Bernacer et al, 2013).

To further test for DA abnormalities, additional studies have used positron emission tomography (PET) with DAspecific ligands, including measures of D1 and D2-type receptors, DA synthesis capacity, and the DA transporter (DAT). In depression, these studies have been fairly mixed, with little clear evidence supporting gross alterations in expression of DA-related proteins (for a recent review, see 
Treadway and Pizzagalli, 2014). In some cases, increased striatal D2/D3 receptor binding has been shown to occur in heterogeneous depressed samples (D'Haenen and Bossuyt, 1994; Shah et al, 1997), whereas other studies have found no change (Hirvonen et al, 2008; Parsey et al, 2001). Importantly, null findings have occurred in unmedicated samples, with one additional small study reporting changes in D2-like binding following treatment with SSRIs (Klimke et al, 1999). One study reported reduced D1 availability in left middle caudate (Cannon et al, 2009), but this finding has not yet been replicated. In addition, only a few studies have looked at symptom-specific relationships with DA proteins. Interestingly, two such studies found evidence for reduced DA synthesis capacity in the striatum only in depressed individuals with flat affect or psychomotor slowing, but not in depressed individuals without these symptoms (Bragulat et al, 2007; Martinot et al, 2001).

In schizophrenia, PET imaging measures suggesting altered DA function have been much more robust, with significant evidence for increased striatal DA synthesis capacity and amphetamine-induced release (Abi-Dargham et al, 1998; Fusar-Poli and Meyer-Lindenberg, 2012). Importantly, these effects are in the opposite direction as those observed in depression or following exposure to an inflammatory stimulus (as discussed below). That said, the overwhelming evidence of blunted striatal responses to reward-related stimuli in schizophrenia-whereas not a direct measure of DA-strongly suggest that the enhanced DA synthesis capacity is likely dysregulated in the striatum, which may contribute to negative symptoms.

In sum, current conceptualizations of DA signaling suggest a critical integration of value and action. This view strongly supports the hypothesis that alterations within DA systems would produce changes in motivation and psychomotor function. A large literature now exists supporting the presence of altered reward-related behavior and associated striatal responses in clinical populations. The question remains, however, as to how these putatively DAergic abnormalities may develop, and whether they might be related to increased inflammation.

\section{INCREASED INFLAMMATION IN PSYCHIATRIC DISORDERS}

\section{Peripheral and Central Cytokines, and Acute-Phase Reactants}

A growing body of evidence suggests that inflammatory mediators and cytokines are increased in a number of patients with psychiatric disorders, which may contribute to DAergic dysfunction and behavioral changes in these patients. Numerous studies have reported increased circulating inflammatory cytokines, such as interleukin (IL)-1, IL-6, and tumor necrosis factor (TNF), their soluble receptors, and acute-phase reactants, such as C-reactive protein (CRP), in patients with MDD (Maes, 1999; Maes et al, 1992; Sluzewska, 1999). These findings have been corroborated by meta- analyses (Dowlati et al, 2010; Howren et al, 2009). Although mood disorders may have complex pathophysiology with heterogeneous etiologies, it is thought that increased inflammation may be involved in the disease process and contribute to discreet symptomologies in a subset of patients. Indeed, recent studies have indicated that high inflammation (plasma CRP concentrations $>3 \mathrm{mg} / \mathrm{l}$, as defined by the American Heart Association; Ridker, 2003) is consistently found in 20$40 \%$ of patients with MDD, with higher concentrations observed in patients who are resistant to standard antidepressant therapies (Felger et al, 2016; Haroon et al, 2016; Raison et al, 2013a; Raison et al, 2013b; Rapaport et al, 2016). Similar increases in inflammatory cytokines and acute-phase reactants have also been reported in patients with bipolar disorder and schizophrenia, including meta-analyses (Goldsmith et al, 2016b; Miller et al, 2011; Potvin et al, 2008). Increased inflammatory cytokine concentrations in the cerebrospinal fluid (CSF) of patients with unipolar and bipolar depression, and schizophrenia have also been observed (Garver et al, 2003; Levine et al, 1999; Schwieler et al, 2015; Soderlund et al, 2011; Soderlund et al, 2009). In MDD, CSF cytokines have been shown to be associated with the severity of depression or with the change in symptoms in response to successful treatment (Levine et al, 1999; Lindqvist et al, 2009; Martinez et al, 2012). In schizophrenia, increased cytokines have been associated with delayed treatment response (Garver et al, 2003), and in bipolar disorder, they are higher in patients that have had more recent manic or hypomanic episodes (Soderlund et al, 2011).

\section{Gene Expression and Genetic Predisposition}

Several functional allelic variants and single-nucleotide polymorphisms of genes encoding immune and inflammatory molecules have been associated with depression and schizophrenia, including those encoding the expression of inflammatory cytokines, major histocompatibility complex proteins, $\mathrm{B}$ and $\mathrm{T}$ cells, and inflammatory mediators such as cyclo-oxygenase2 (Bamne et al, 2012; Bosker et al, 2011; Bufalino et al, 2012; Raison and Miller, 2013; Schizophrenia Working Group of the Psychiatric Genomics, 2014). These findings have engendered speculation as to whether alleles that promote enhanced inflammatory cytokine secretion were evolutionarily advantageous and thus conserved (Raison and Miller, 2013). Indeed, heightened inflammatory responses to environmental stimuli may have improved survival by conferring greater protection from bacterial and viral infection (Raison and Miller, 2013), and genetic priming to respond to stress and the environment with increased inflammatory and antiviral responses could contribute to the high prevalence of psychiatric disorders comorbid with medical illnesses that are associated with inflammation (eg, cardiovascular disease, metabolic disorders, and autoimmune disorders) (Evans et al, 1999; Pollak and Yirmiya, 2002; Raison and Miller, 2003; Shelton and Miller, 2010; Yirmiya et al, 2000; Yirmiya et al, 1999). 
In addition to genetic polymorphisms, increased inflammatory gene expression in circulating immune cells has been found in patients with depression and other psychiatric disorders (Chase et al, 2015; Fillman et al, 2014; Mostafavi et al, 2014) and may predict treatment response. For instance, a targeted analysis of leukocyte mRNA expression of a subset of genes related to inflammation, glucocorticoid receptor signaling, and neuroplasticity revealed higher baseline mRNA levels of IL-1 $\beta$, macrophage inhibitory factor, and TNF in patients with depression who failed to respond to 8 weeks of treatment with escitalopram or nortriptyline (Cattaneo et al, 2013). Interestingly, increased expression of a number of inflammatory markers has been observed in the brains of patients with both mood disorders and schizophrenia (Fillman et al, 2014; Shelton et al, 2011).

\section{Peripheral and Central Immune Cell Activation}

Peripheral inflammatory cytokines may access the CNS to initiate local immune activation by several mechanisms, including (1) passage through leaky regions in the bloodbrain barrier at circumventricular organs (Katsuura et al, 1990; Pan and Kastin, 2003), (2) active uptake mechanisms of cytokines across the blood-brain barrier (Banks and Erickson, 2010; Banks et al, 2002; Banks et al, 1995), and (3) local actions at peripheral vagal nerve afferents that relay cytokine signals to relevant brain regions, including the nucleus of the solitary tract and hypothalamus (the so-called 'neural route'; Bluthe et al, 1994; Ericsson et al, 1994; Watkins et al, 1995; Watkins et al, 1994). However, recent translational data indicate that during peripheral inflammation, activated monocytes/macrophages traffic to the brain in response to monocyte chemoattractant protein-1 (MCP-1), a chemokine produced by activated microglial cells in response to cytokine signaling in from the periphery (D'Mello et al, 2009; D'Mello et al, 2015). These monocytes/macrophages traffic primarily to perivascular and meningeal spaces, and have been shown to contribute to the behavioral changes in rodent models of stress-induced depressive and anxiety behaviors (Hodes et al, 2014; Wohleb et al, 2012; Wohleb et al, 2014). Interestingly, patterns of gene expression in the peripheral blood of patients with psychiatric disorders exhibit increased signatures consistent with proinflammatory ' $\mathrm{M1}$ ' activation of monocyte/macrophages (Brambilla et al, 2014; Drago et al, 2015; Mostafavi et al, 2014). Furthermore, the recruitment of activated peripheral macrophages to perivascular spaces, as well as localized activation of microglia neighboring theses blood vessels and increased expression of MCP-1, has been observed in the dorsal ACC of post-mortem tissue from suicide patients with mood disorders (Steiner et al, 2011; Torres-Platas et al, 2014). These findings indicate that accumulation of peripheral immune cells in vascular compartments in association with restricted and/or regionally specific activation of microglia may be characteristic of patients with mood disorders who exhibit high inflammation.

\section{In vivo Imaging of CNS Immune Cell Activation in Psychiatric Disorders}

With such strong evidence for increased inflammatory markers at the periphery of patients with psychiatric illness, there has been growing interest in finding ways to more directly measure activation of inflammatory processes in the brain. Despite intense efforts, however, the direct in vivo assessment of activation of immune cells in the CNS has remained somewhat elusive. One primary strategy has been the development of radioligands that bind to macrophage as well as activated microglia in the brain. Microglia were previously believed to exist primarily in two states: dormant or activated (Tremblay et al, 2011). In the latter state, microglia increase surface expression of the translocator protein (TSPO), which could therefore be used as a potential marker of activated microglia. Consistent with this, PET ligands that bind to TSPO, such as $\left[{ }^{11} \mathrm{C}\right] \mathrm{PK}$ 11195, show elevated non-displaceable-binding potential $\left(\mathrm{BP}_{\mathrm{ND}}\right.$; Lockhart et al, 2003) and have been used to assess microglia activation in animal models of neuroinflammation (Cagnin et al, 2007; Venneti et al, 2007). Unfortunately, the specific activity of PK 11195 is too low to detect subtler inflammatory effects. More recently, second-generation TSPO ligands such as $\left[{ }^{11} \mathrm{C}\right]$ PBR28 (Imaizumi et al, 2007) and $\left[{ }^{18} \mathrm{~F}\right] \mathrm{FEPPA}$ (Wilson et al, 2008) have been developed that partially address this problem, and have been used to test for activated CNS immune cells in patients with depression and schizophrenia with mixed results (Bloomfield et al, 2015; Hannestad et al, 2012b; Kenk et al, 2015; Setiawan et al, 2015). In a sample of mildmoderate depression using the $\left[{ }^{11} \mathrm{C}\right] \mathrm{PBR} 28$, Hannestad et al (2012b) found no difference between patients and controls in $\mathrm{BP}_{\mathrm{ND}}$, though the sample was small and the depression severity was relatively low. In contrast, Setiawan et al (2015) used the $18 \mathrm{~F}$ analog of $\left[{ }^{11} \mathrm{C}\right]$ PBR $28-\left[{ }^{18} \mathrm{~F}\right] \mathrm{FEPPA}-$ to examine the microglia activity in a more severely depressed sample, and observed significant increases in $\mathrm{BP}_{\mathrm{ND}}$ in the striatum, hippocampus, insula, and prefrontal areas (Setiawan et al, 2015). Similar inconsistencies have been observed in schizophrenia, where one study found no difference between actively psychotic patients and healthy controls (Kenk et al, 2015), and another found large global increases in TSPO binding in both diagnosed schizophrenia patients as well as individuals at clinical high risk (Bloomfield et al, 2015).

Although these studies provide some preliminary support for the tantalizing possibility of more directly visualizing activated immune cells in the CNS, several caveats are worth mentioning. First, microglia are not as 'dormant' as once believed, and are now known to have a variety of ongoing sentinel-type functions (Tremblay et al, 2011). Moreover, microglia exhibit a graded response of activation (Raivich et al, 1999), and increases in some activation markers-such as TSPO-may not indicate a true inflammatory phenotype (Marshall et al, 2013; Saijo and Glass, 2011). Consequently, the distinction between normally $v s$ pathologically active microglia may be difficult to resolve solely on the basis of TSPO expression. In addition, within patient samples, there 
has been no evidence linking $\mathrm{TSPO} \mathrm{BP}_{\mathrm{ND}}$ to peripheral cytokine concentrations. This may be an artifact of the volume transmission analysis model, as TSPO $\mathrm{BP}_{\mathrm{ND}}$ is determined through the use of an arterial input function. Given the wide distribution of TSPO, it is possible that evidence of increased inflammation may also be associated with elevated TSPO expression outside the CNS. If this is the case, then the use of an arterial input function may obscure associations between peripheral and central inflammatory measures. That being said, two studies have established that TSPO binding is highly sensitive to an acute inflammatory challenge in both human and non-human primates (Hannestad et al, 2012a; Sandiego et al, 2015).

In sum, although PET measures of immune cell activation in the CNS in clinical samples provide some evidence that inflammation impacts DA-rich areas such as basal ganglia and ACC, as well as other cortical and subcortical structures, further studies are needed to validate the efficiency of TSPO ligands as markers of inflammation in the brain in psychiatric states as well as their relationships to peripheral measures of inflammation and clinical symptom profiles.

\section{Sources of Innate Immune Activation and Inflammation}

Factors that may activate the innate immune system and contribute to increased inflammation in psychiatric patients who are otherwise medically stable include psychosocial stress (and particularly early life stress), sleep disturbance, inflammatory diet and gastrointestinal permeability, obesity, and other lifestyle factors such as smoking (Berk et al, 2013). Subjects with a history of childhood trauma exhibit elevated inflammatory biomarkers and higher rates of depression as adults (Danese et al, 2008; Danese et al, 2007), and a 'biological embedding' or imprinting of stress through inflammatory processes in childhood has been proposed (Danese et al, 2011; Nusslock and Miller, 2015). For instance, subjects with MDD and a history of early life stress responded to psychological stress (the Trier Social Stress Test), with exaggerated circulating IL- 6 production and increased DNA binding of nuclear factor- $\mathrm{kB}$ in peripheral blood mononuclear cells compared with non-depressed controls (Pace et al, 2006). Increased IL-6 production in adolescents with histories of childhood adversity has been shown to precede subsequent development of depression 6 months later (Miller and Cole, 2012), indicating causal relationships between early life stress, increased inflammation, and depression. Sleep disturbance may be another variable that is related to inflammation (Bryant et al, 2004; Motivala et al, 2005; Opp et al, 2007; Suarez, 2008). Sleep deprivation results in increased circulating levels of IL-6, TNF, and CRP when compared with periods of undisturbed sleep (Meier-Ewert et al, 2004; Vgontzas et al, 1999; Vgontzas et al, 2004). Disturbed sleep also increase circulating IL-6, TNF, and CRP (Meier-Ewert et al, 2004; Vgontzas et al, 1999; Vgontzas et al, 2004), and sleep impairments in psychiatric illnesses such as depression have been associated with increased inflammation (Bryant et al, 2004; Motivala et al, 2005; Opp et al, 2007; Suarez, 2008).

In terms of lifestyle factors, inflammatory diets that promote gut permeability and changes in the microbiota, smoking, and increased body mass index (BMI) all contribute to increased inflammation and may interact with genetics and stress to contribute to behavioral symptoms and poor overall health outcomes in patients with psychiatric illness (Berk et al, 2013; Jamal et al, 2014). For example, obesity from consumption of a high-fat diet in rodents induces changes in the gut microbiota and increases ileal inflammation and permeability (de La Serre et al, 2010). Obesity and high BMI are associated with increased concentrations of IL- 6 and other inflammatory markers in humans (Khaodhiar et al, 2004; Lim et al, 2005) thought to be the result of macrophage accumulation in adipose tissue, and especially visceral adiposity, which can release cytokines into portal circulation (Park et al, 2005; Suganami and Ogawa, 2010; Weisberg et al, 2003). Interestingly, adiposity has been suggested as a link between psychiatric illness, increased inflammatory markers, and increased risk of coronary heart disease (Miller et al, 2003; Miller et al, 2002).

\section{INFLAMMATION-INDUCED IMPAIRMENTS IN MOTIVATION AND MOTOR ACTIVITY - LINKS TO STRIATAL DA FUNCTION}

A wealth of data suggests that alterations in motivation and motor function may be driven by increased inflammation via effects on reward circuitry and DA. In humans, much of this evidence stems from studies in healthy volunteers acutely administered inflammatory stimuli (eg, endotoxin or typhoid vaccination) and from patients chronically administered inflammatory cytokines (eg, IFN- $\alpha$ ) as therapy for some cancers and infectious diseases. Like endotoxin and vaccination, IFN- $\alpha$ administration induces release of the inflammatory cytokines IL-6, IL-1, and TNF (Capuron et al, 2003b; Felger et al, 2007; Raison et al, 2009; Sissolak et al, 1992; Taylor and Grossberg, 1998). Depending on the dose, up to $50 \%$ of patients administered IFN- $\alpha$ as treatment for hepatitis $\mathrm{C}$ virus (HCV) or malignant melanoma meet symptom criteria for major depression, and up to $80 \%$ experience significant fatigue, lack of energy, and motor slowing (Capuron et al, 2002a; Capuron et al, 2002b; Capuron et al, 2003a; Donnelly, 1998; Musselman et al, 2001; Raison et al, 2005a; Raison et al, 2009; Raison et al, 2010b). In addition, reduced motivation and anhedonia are frequently reported in IFN- $\alpha$-treated patients (Capuron $e t$ al, 2002a; Capuron et al, 2012; Majer et al, 2008). Indeed, targeted instruments that assess aspects of anhedonia, including the Snaith-Hamilton Pleasure Scale and Reduced Motivation subscale of the Multidimensional Fatigue Inventory (MFI), have yielded comparable effect sizes (all $r=0.47-0.49)$ as for increases in self-reported depression or fatigue scores after chronic IFN- $\alpha$ treatment (Capuron et al, 2012; Majer et al, 2008). 
Although the role of inflammation in psychiatric disorders has been studied primarily in comparison to healthy controls or as a function of overall disease severity, the few studies that have examined relationships between inflammatory markers and symptom dimensions reveal evidence of associations between increased inflammation and reduced motivation and motor function. For example, in patients from a high-risk urban setting with a history of trauma, those who carried a CRP genotype (rs1130864) that is associated with elevated CRP concentrations had higher rates of posttraumatic stress disorder and reported higher scores for the loss of interest in activities (Michopoulos et al, 2015). Furthermore, recent data indicate that increased plasma concentrations of CRP and inflammatory cytokines and their soluble receptors correlate with symptoms of both anhedonia and psychomotor slowing in medically stable patients with MDD (Felger et al, 2016; Goldsmith et al, 2016a; Haroon et al, 2016). These findings provide encouraging data that increased inflammation may be associated with symptoms of motivation and motor behavior across disorders, and may be useful for identifying subtypes of patients with psychiatric illness. Both clinical and translational evidence support the hypothesis that the impact of inflammation on motivation and motor function is driven by cytokine effects on DAergic systems, as reviewed below.

\section{Biochemical and Behavioral Studies in Laboratory Animals}

Initial evidence that inflammation can affect brain DA originates from neurochemical and behavioral studies in rodents administered acute or subchronic IFN- $\alpha$ that measured DA and/or DA metabolites in concert with depressive behaviors and changes in locomotor activity (Kamata et al, 2000; Kitagami et al, 2003; Kumai et al, 2000; Sato et al, 2006; Shuto et al, 1997). Some studies reported increases (Kumai et al, 2000; Sato et al, 2006), whereas others have reported decreases (Kamata et al, 2000; Kitagami et al, 2003; Shuto et al, 1997) in brain DA and/or metabolites following acute or subchronic IFN- $\alpha$ administration. These discrepancies were likely due to differences in dosing, length of exposure, and, most importantly, the fact that speciesspecific IFN- $\alpha$ was variably used and rodents do not respond to human IFN- $\alpha$ with activation of classic type I IFN receptor signaling (Loftis et al, 2006a; Loftis et al, 2006b; Wang et al, 2008). Moreover, human IFN- $\alpha$ administered to rodents binds to opioid receptors, which may be responsible for some of the observed changes in brain monoamines (Blalock and Smith, 1981; Ho et al, 1992; Wang et al, 2006). Moreover, chronic (6 days to 4 weeks) peripheral administration of both human- and species-specific IFN-a administered to rodents has demonstrated only limited ability to reliably induce depressive behaviors (eg, see Fahey et al, 2007, Guo et al, 2016, Kosel et al, 2011,Loftis et al, 2006a,Loftis et al, 2006b,Makino et al, 2000a,Makino et al, 2000b,Orsal et al, 2008 and Zheng et al, 2014.
Rhesus monkeys exposed to chronic IFN- $\alpha$ exhibit immune, neuroendocrine, and behavioral responses similar to that of cytokine-treated patients, including decreases in psychomotor activity and increases in depressive-like huddling behavior (in 50\% of animals; Felger et al, 2007; Felger and Miller, 2012). Of note, depressive huddling behavior in non-human primates has been previously described following chronic administration of the monoamine-depleting agent reserpine, and DA receptor antagonists and partial agonists (McKinney et al, 1971; Rosenzweig-Lipson et al, 1994). Only animals that displayed depressive behavior following IFN- $\alpha$ administration were found to have significantly lower CSF concentrations of the DA metabolites homovanillic acid (HVA) and 3,4-dihydroxy-phenylacetic acid (DOPAC), which also correlated with decreased locomotor activity (Felger et al, 2007; Felger and Miller, 2012). Moreover, chronic IFN- $\alpha$ administration reduced effort-based but not freely available sucrose consumption by the monkeys (Felger et al, 2013c). Similar to the effects of IFN- $\alpha$, peripheral administration of IL- $1 \beta$ to rodents has been shown to decrease effortful responding for sucrose reward over freely available chow, in the absence of a decrease in preference for freely available sucrose over chow (Nunes et al, 2014); an effect that was reversed by lisdexamfetamine (Yohn et al, 2016). Interestingly, peripheral administration of IL- $1 \beta$ in mice at $24 \mathrm{~h}$ has been shown to decrease locomotor (wheel running) activity, which was improved by methylphenidate but not modafinil (Bonsall et al, 2015). Furthermore, similar to IL- $1 \beta$ administration, an overall decrease in responding for food reward has been reported in mice following peripheral administration of lipopolysaccharide (LPS; ie, endotoxin) with no decrease in reward sensitivity (preference for high value sucrose rewards) (Vichaya et al, 2014).

To further explore the effects of inflammatory cytokines on synaptic availability and release of striatal DA that may underlie inflammation effects on motivation and motor function, in vivo microdialysis was conducted on IFN- $\alpha$ treated monkeys (Felger et al, 2013c). Results indicated that stimulated DA release was indeed decreased in the striatum after chronic administration of IFN- $\alpha$, which correlated with reduced effort-based sucrose consumption (Felger et al, 2013c). Furthermore, IFN- $\alpha$-induced decreases in striatal DA release were reversed by the DA precursor levodopa (L-DOPA) administered via reverse in vivo microdialysis, indicating that cytokines may reduced DA synthesis and availability (Felger et al, 2015). In addition to IFN- $\alpha$ administration, models of peripheral inflammation in rodents have also been shown to decrease DA availability. For example, single injections of septic doses of LPS ( $5 \mathrm{mg}$ / $\mathrm{kg}$ ) cause progressive neurodegeneration of the nigrostriatal DArgic system (Qin et al, 2007; Reinert et al, 2014). It should be noted that acute systemic administration of low-dose LPS $(\sim 100 \mu \mathrm{g} / \mathrm{kg})$ has been reported to either decrease tissue DA content or increase extracellular DA metabolites in the NAcc (van Heesch et al, 2014; Yeh et al, 2015). However, these studies assessed DA and 'anhedonic' behavior (sucrose 
preference or responding for brain stimulation) at 2-4 h post LPS (van Heesch et al, 2014; van Heesch et al, 2013; Yeh et al, 2015), a time point that may be confounded due to the febrile effects of LPS and related sickness behaviors (Dinarello, 2004; Frenois et al, 2007; O'Connor et al, 2009b). These early effects of LPS may also reflect, for instance, acute activation of neuroendocrine peptides and hormones (minutes to hours), which can have stimulatory effects on turnover or release of brain catecholamines (Barrot et al, 2000; Lavicky and Dunn, 1993; Matsuzaki et al, 1989; Mekaouche et al, 1996), and which may occur ahead of the more chronic mechanisms by which inflammation is thought to contribute to decreased DA availability (see the section 'Mechanisms of inflammation effects on dopamine synthesis and release' below for detailed discussion). Nevertheless, both the short- and long-term effects of LPS on brain DA can be blocked by inhibition or genetic deletion of inflammatory cytokines such as TNF (Qin et al, 2007; Tian et al, 2006; van Heesch et al, 2014). Even localized inflammation in the hind paw following carrageenan administration has been shown to decrease DA release in the insula (Coffeen et al, 2010). Finally, models of inflammation-related medical illness, such as experimental tumors, are associated with decreased brain
DA (Lebena et al, 2014; Uomoto et al, 1998). Together, these results from animal studies indicate that a variety of inflammatory stimuli have been consistently found to affect brain DA to lead to relevant behavioral symptoms, and have prompt further investigation into inflammation effects on DA and the basal ganglia in clinical populations.

\section{Neuroimaging of the DA System and Corticostriatal Reward Circuitry}

Neuroimaging studies across several laboratories suggest that disruption of the basal ganglia and DA is a major contributor to inflammation-induced behavioral change (Table 1). In the first study to examine IFN- $\alpha$ effects on the brain, in addition to the decreased metabolism in PFC, increased glucose metabolism was found in the basal ganglia and particularly the DA-rich putamen (Juengling et al, 2000), as assessed by PET neuroimaging with fluorine-18-labeled fluorodeoxyglucose (FDG). More recently, FDG PET revealed increased basal ganglia glucose metabolism in patients receiving highdose IFN- $\alpha$ as therapy for malignant melanoma (Capuron et al, 2007). Increased glucose metabolism in the left putamen and left NAcc correlated significantly with the

TABLE 1 Summary of Findings from Neuroimaging Studies Examining the Effect of Administration of Inflammatory Stimuli or Cytokines on Dopamine and/or Reward Circuitry

\begin{tabular}{|c|c|c|c|c|c|}
\hline Neuroimaging technique & Subjects & $\begin{array}{l}\text { Inflammatory } \\
\text { stimulus }\end{array}$ & Region & Finding & Study \\
\hline \multicolumn{6}{|l|}{$\overline{P E T}$} \\
\hline [18F]FDOPA, turnover & $\mathrm{HCV}+$ patients & $4-6$ weeks IFN- $\alpha$ & VS, DS & $\downarrow$ & Capuron et al, 2012 \\
\hline [18F]FDG, glucose metabolism & $\mathrm{HCV}+$ patients & 12 weeks IFN- $\alpha$ & DS & $\uparrow$ & Juengling et al, 2000 \\
\hline [I8F]FDG, glucose metabolism & MM patients & 4 weeks IFN- $\alpha$ & PFC & $\downarrow$ & Capuron et al, 2007 \\
\hline [I IC]raclopride, D2R binding & Rhesus monkeys & 4 weeks IFN- $\alpha$ & VS, DS & $\downarrow$ & Felger et al, $2013 c$ \\
\hline [ I IC]raclopride, AMPH displacement & Rhesus monkeys & 4 weeks IFN- $\alpha$ & VS, DS & $\downarrow$ & Felger et $a l, 2013 c$ \\
\hline \multicolumn{6}{|l|}{ FMRI/MRI } \\
\hline Activation to positive social feedback & Healthy controls & Endotoxin & VS, vmPFC & $\uparrow$ & Muscatell et al, 2016 \\
\hline Activation to RPEs (probabilistic learning) & Healthy controls & Vaccination & VS & $\downarrow$ & Harrison et al, 20।5b \\
\hline Activation to PPEs (probabilistic learning) & Healthy controls & Vaccination & $\mathrm{Al}$ & $\uparrow$ & Harrison et al, 20I5b \\
\hline Activation to cognitive Stroop & Healthy controls & Vaccination & SN & $\uparrow$ & Brydon et al, 2008 \\
\hline Activation to visual stimuli & Healthy controls & Vaccination & SN & $\downarrow$ & Brydon et al, 2008 \\
\hline Activation to novel stimuli & Healthy controls & Vaccination & SN & $\downarrow$ & Harrison et al, 20।5a \\
\hline qMT- $k_{f}$ & $\mathrm{HCV}+$ patients & $4 \mathrm{~h} \mathrm{IFN- \alpha}$ & VS, DS & $\uparrow$ & Dowell et al, 2016 \\
\hline $\mathrm{qMT}-T_{2 f}$ & $\mathrm{HCV}+$ patients & $4 \mathrm{~h} \mid \mathrm{FN}-\alpha$ & VS, DS & $\downarrow$ & Dowell et al, 2016 \\
\hline
\end{tabular}

Abbreviations: $\uparrow$, increased; $\downarrow$, deceased; Al, anterior insula; AMPH, amphetamine; D2R, dopamine 2 receptor; DS, dorsal striatum; FDG, fludeoxyglucose; FDOPA, fluorodopa; $\mathrm{PMRI}$, functional magnet resonance imaging; $\mathrm{HCV}$, hepatitis C virus; IFN, interferon; $\mathrm{k}_{\mathrm{f}}$, rate magnetization transfer from free (water) to molecular-bound protons; MIDT, monetary incentive delay task; MM, malignant melanoma; PET, positron emission tomography; PFC, prefrontal cortex; PPE, punishment prediction error; qMT, quantitative magnetization transfer, RPE, reward prediction error, $S N$, substantia nigra; $T_{2 f}$, free water spin-spin relaxation time; vmPFC, ventromedial prefrontal cortex; VS, ventral striatum. 
reports of fatigue in these patients, as assessed by the 'energy' subscale of the Visual Analog Scale of Fatigue (Capuron et al, 2007). This pattern of increased glucose metabolism in basal ganglia nuclei is similar to that seen in patients with PD (Eidelberg et al, 1994; Mentis et al, 2002; Spetsieris et al, 1995), where it is thought to reflect increased oscillatory burst activity in relevant basal ganglia nuclei secondary to the loss of inhibitory nigral DA input (Wichmann and DeLong, 1999,2003). Interestingly, this pattern of increased metabolism in striatum is also similar to the effects of transient catecholamine depletion in patients with MDD reported by Hasler et al (2008), which correlated with anhedonic symptoms.

fMRI conducted by Capuron and colleagues has also demonstrated decreased neural activation in the basal ganglia, including ventral striatum, to unexpected delivery of reward (winning in a gambling task (Reuter et al, 2005)) in $\mathrm{HCV}+$ patients undergoing IFN- $\alpha$ administration, which correlated with self-reported reduced motivation (Capuron et al, 2012). Acute administration of IFN- $\alpha$ has also been shown to induce a change in striatal microstructure, as measured by quantitative magnetization transfer imaging, that predicted an increase in symptoms of fatigue (Dowell et al, 2016). Administration of the cytokine inducers endotoxin and typhoid vaccination to healthy volunteers produces similar effects on the ventral striatum in response to rewarding stimuli, suggesting that findings from IFN- $\alpha$ generalize to other inflammatory stimuli (Eisenberger et al, 2010; Harrison et al, 2015b). Indeed, Eisenberger et al (2010) demonstrated that endotoxin administration led to the reduced activation of ventral striatum to reward-predicting cues during a monetary incentive delay task, which was associated with increases in self-reported depressed mood as measured by the Profile of Mood States depression subscale. Similar blunting of neural responses to reward anticipation has been observed following dietary depletion of precursors for DA synthesis (Bjork et al, 2014). Moreover, typhoid vaccination was found to cause a shift in reward $v s$ punishment sensitivity in a probabilistic instrumental learning task combined with fMRI (Harrison et al, 2015b). Compared with saline control, Harrison et al, 2015b determined that vaccination reduced behavioral attractiveness of rewards while making punishments more aversive, effects that were related to decreased neural activation of ventral striatum to RPEs, and increased activation of anterior insula to punishment prediction errors. Of relevance to potential effects of inflammation on DA and as discussed in the section 'Normal and abnormal dopamine function in the context of motivation and psychomotor function' above, the magnitude of response to prediction error signaling is fundamentally modulated by a DA-dependent striatal activity as determined by the administration of drugs that enhance (L-DOPA) or inhibit (haloperidol) DAergic function (Pessiglione et al, 2006). In addition, typhoid vaccination compared with saline has been shown to affect activity in the substantia nigra, including increased activation during a cognitive Stroop task and decreased activation in response to visual or novel stimuli, which correlated with both psychomotor slowing and increased peripheral blood concentrations of IL-6 (Brydon et al, 2008; Harrison et al, 2015a). Finally, it should be mentioned that neural activation in reward circuitry (ventral striatum and ventromedial PFC (vmPFC)) has also been shown to encode endotoxin-induced increased sensitivity to social rewards, including positive social feedback and increased approach to familiar others (Inagaki et al, 2015; Muscatell et al, 2016).

To further examine the role of DA in the effects of inflammation on neural activation and metabolism in reward circuitry, Capuron et al (2012) conducted a PET study in $\mathrm{HCV}+$, IFN- $\alpha$-treated subjects using $\left[{ }^{18} \mathrm{~F}\right]$ fluorodopa (FDOPA). Like the DA precursor L-DOPA, FDOPA is taken up by DAergic neurons and converted by DA decarboxylase to DA, whereupon it is stored in vesicles for release. Interestingly, both increased uptake and decreased turnover of FDOPA in the caudate, putamen, and ventral striatum of IFN- $\alpha$-treated patients were found (Capuron et al, 2012). Baseline and percent change in FDOPA uptake was in turn correlated with IFN- $\alpha$-induced behavioral alterations including depression and fatigue, as measured by the Montgomery Asberg Depression Rating Scale (MADRS) and MFI, respectively (Capuron et al, 2012). Increased uptake and decreased turnover of FDOPA in the basal ganglia following IFN- $\alpha$ administration are in stark contrast to that observed in patients with PD, where decreased uptake and increased FDOPA turnover are seen. Decreased uptake of FDOPA in $\mathrm{PD}$ is believed to be a function of the loss of DAergic neurons and/or their projections throughout the basal ganglia (Kaasinen et al, 2001; Kumakura and Cumming, 2009; Leenders et al, 1986), and intact or increased turnover suggests that the surviving neurons are capable of normal release (Kumakura and Cumming, 2009; Kumakura et al, 2006). Increased FDOPA uptake during IFN- $\alpha$ treatment suggests intact terminals that exhibit a potential depletion of DA and increased synthetic capacity. These findings are consistent with that of the decreased striatal DA release observed in IFN- $\alpha$-treated monkeys, as measured by both $\left[{ }^{11} \mathrm{C}\right]$ raclopride PET with amphetamine displacement (in putamen and NAcc) and in vivo microdialysis-which was reversed by L-DOPA administration (see above; Felger et al, 2015; Felger et al, 2013c).

Despite the abundance of reports indicating changes in basal ganglia and DA function in subjects administered cytokines and inflammatory stimuli, little work has been done to investigate similar effects of inflammation in patients who exhibit high inflammation, as a function of medical or neuropsychiatric illnesses. One study in patients with chronic fatigue syndrome, who have been frequently reported to exhibit elevated inflammatory markers including cytokines, observed decreased activation of basal ganglia structures, such as caudate and globus pallidus, in response to hedonic reward using the gambling task mentioned above (Miller et al, 2014). In medically stable patients with MDD, we observed a relationship between increased inflammation and decreased functional connectivity within reward-related 
corticostriatal neurocircuitry (Felger et al, 2016). Indeed, increased inflammation (plasma concentrations of CRP as well as cytokines and their soluble receptors) was associated with decreased functional connectivity between the ventral striatum and vmPFC, and the dorsal striatum and the vmPFC and pre-supplementary motor area (pre-SMA), which correlated with self-reported symptoms of anhedonia and objective measures of psychomotor slowing, respectively (Felger et al, 2016). Interestingly, dorsal striatum and preSMA/SMA are key components of corticostriatal circuitry involved in linking motivation to motor output (Haber and Knutson, 2010; Samanez-Larkin and Knutson, 2015), and like the ventral striatum, vmPFC is part of classic reward circuitry that receives significant mesocorticolimbic DA innervation (Diekhof et al, 2012; Russo and Nestler, 2013). Accordingly, inflammation-related decreases in corticostriatal connectivity within reward and motor circuitry in depression may involve cytokine-induced decreases in DA, and have potential for reversal with pharmacological strategies that increase DA availability or receptor signaling (see the sections 'Mechanisms of inflammation effects on dopamine synthesis and release' and 'Potential therapeutic targets for inflammation effects on dopamine' below for further discussion; Felger and Miller, 2012).

Together, these data from humans and laboratory animals indicate that inflammation-related decreases in DA availability and release may have functional consequences on reward circuitry that are associated with fundamental alterations in motivation and motor function, to contribute to symptoms of anhedonia and psychomotor retardation (Figure 1). This work supports further consideration of the mechanisms of cytokine effects on DA synthesis, release, reuptake, or receptor signaling, which may lead to the development of novel therapeutic strategies to increase DA availability in patients with increased inflammation.

\section{MECHANISMS OF INFLAMMATION EFFECTS ON DA SYNTHESIS AND RELEASE}

Inflammation and cytokines can potentially affect multiple aspects of DA function, leading to decreased synthesis, impaired packaging and release, increased reuptake, or decreased DA receptors, all of which may interact to a greater or lesser extent to reduce DA signaling in the basal ganglia (see Figure 2). Accordingly, the following section will discuss potential mechanisms by which inflammation may affect DA neurotransmission.

\section{DA Synthesis and Availability}

DA synthesis relies on the conversion of tyrosine to L-DOPA by tyrosine hydroxylase ( $\mathrm{TH})$, the rate-limiting enzyme for DA synthesis. A major source of tyrosine is phenylalanine, which is converted to tyrosine by phenylalanine hydroxylase $(\mathrm{PAH})$. Both of these enzymes, $\mathrm{TH}$ and $\mathrm{PAH}$, require the enzyme cofactor tetrahydrobiopterin (BH4). Although inflammation and cytokines have been shown to induce GTP

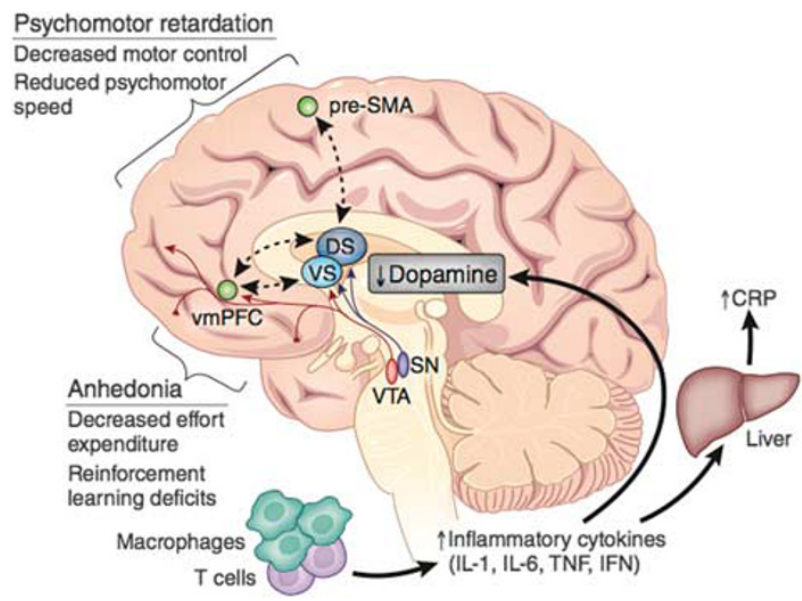

Figure 1. Inflammation-induced decreases in dopamine (DA) may affect corticostriatal reward and motor circuitry to drive symptoms of anhedonia and psychomotor retardation. Peripheral innate immune activation and the release of inflammatory cytokines, and acute-phase reactants (eg, C-reactive protein (CRP)) in patients with major depressive disorder (MDD) have been associated with decreased functional connectivity between the ventral and dorsal striatum and reward and motor-related cortical regions, ventromedial prefrontal cortex (vmPFC) and presupplementary motor area (SMA; Felger et al, 2016). Inflammationrelated changes in corticostriatal connectivity correlated with symptoms of anhedonia and psychomotor retardation, and may involve deficits in DArelevant, goal-directed behaviors such as such effort expenditure, reinforcement learning, and motor control. A wealth of knowledge from studies in humans and animals administered inflammatory stimuli or cytokines indicates that these effects on corticostriatal circuits may be related to inflammation-induced decreases in DA availability and release. CRP, C-reactive protein; DS, dorsal striatum; IFN, interferon; IL, interleukin; SMA, supplementary motor area; SN, substantia nigra; TNF, tumor necrosis factor; vmPFC, ventromedial prefrontal cortex; VS, ventral striatum; VTA, ventral tengmental area.

cyclohydrolase I, the enzyme necessary for BH4 synthesis, inflammation may in turn decrease BH4 availability (Neurauter et al, 2008). BH4 is also a cofactor for nitric oxide synthases (NOS). Inflammation-induced increases in inducible NOS activity can usurp available $\mathrm{BH} 4$, which results in NOS uncoupling and the generation of reactive oxygen species instead of NO (Cunnington and Channon, 2010; Xia et al, 1998). This increase in oxidative stress can then contribute to oxidative reduction of $\mathrm{BH} 4$ itself (which is highly redox sensitive) to 7,8-dihydrobiopterin (BH2), leaving even less BH4 available for DA synthesis (Figure 2) (Cunnington and Channon, 2010). Indeed, intramuscular injection of rats with IFN- $\alpha$ has been shown to decrease CNS concentrations of $\mathrm{BH} 4$ through stimulation of $\mathrm{NO}$, and inhibition of NOS was found to reverse IFN- $\alpha$ 's inhibitory effects on brain concentrations of both $\mathrm{BH} 4$ and DA (Kitagami et al, 2003). Of note, IL-6 treatment has also been shown to reduce $\mathrm{BH} 4$ content in sympathetic neurons ( $\mathrm{Li}$ et al, 2003).

Concentrations of phenylalanine, tyrosine, $\mathrm{BH} 4$, and $\mathrm{BH} 2$ can be measured in the peripheral blood and CSF, and the $\mathrm{BH} 4 / \mathrm{BH} 2$ and phenylalanine/tyrosine ratios have been proposed as indicators of $\mathrm{BH} 4$ availability and $\mathrm{PAH}$ activity, 


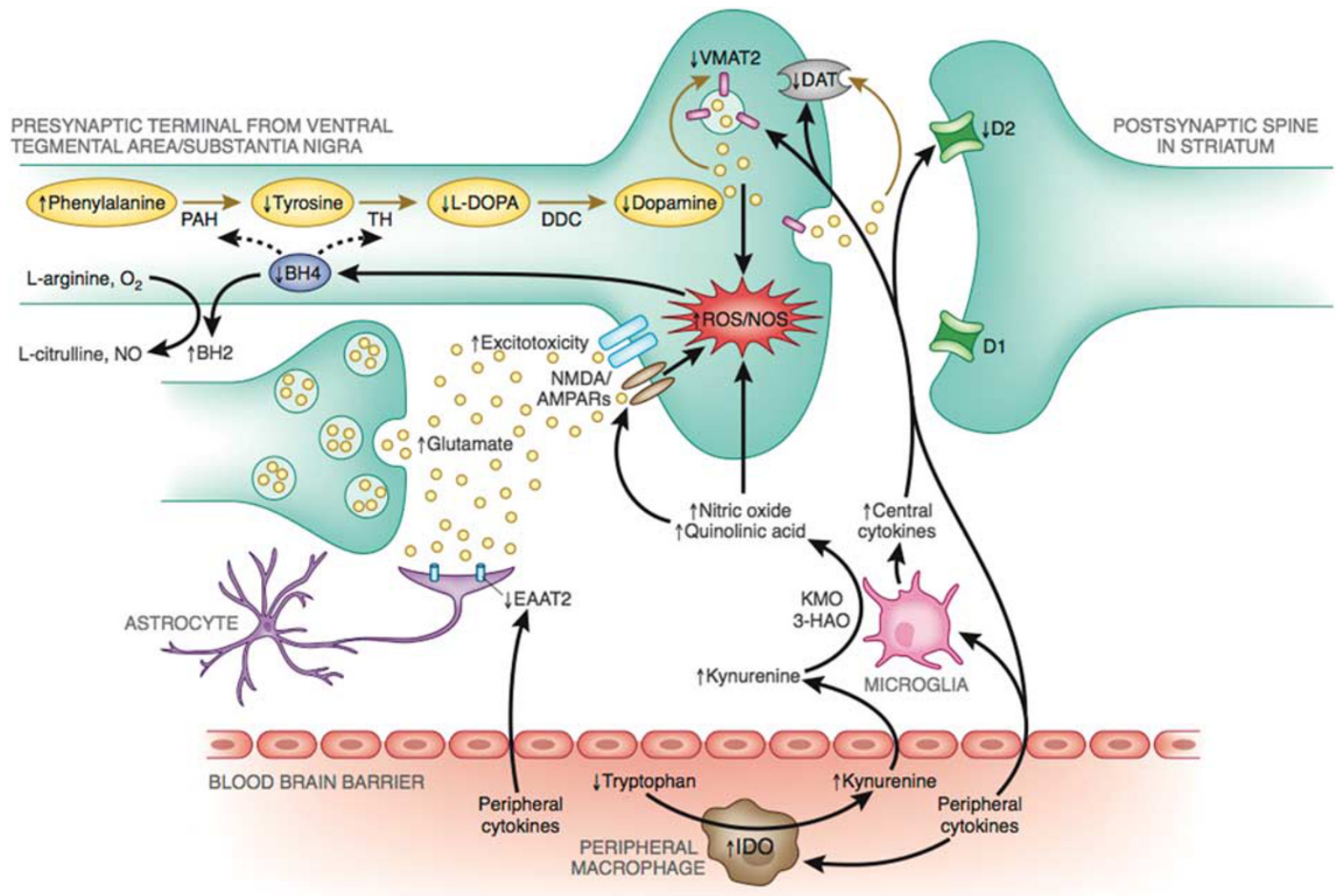

Figure 2. Potential mechanisms of inflammation effects on dopamine (DA) synthesis, release, and receptor signaling. Evidence indicates that inflammation and release of cytokines from the periphery, or those produced locally by activated microglia or infiltrating macrophages, can produce nitric oxide, as well as quinolinic acid through indoleamine 2,3-dioxygenase (IDO) and kynurenine pathways, both of which contribute to oxidative stress, and reactive oxygen species (ROS) generation. Increased $\mathrm{ROS}$ and inflammation-induced nitric oxide contribute to oxidation of tetrahydrobiopterin (BH4), a cofactor required for the conversion of phenylalanine to tyrosine and tyrosine to L-3,4-dihydroxyphenylalanine (L-DOPA), which are necessary for the synthesis of DA. Furthermore, some evidence exists that inflammatory cytokines may decrease the expression or function of the vesicular monoamine transporter 2 (VMAT2) and/or increase expression or function of the dopamine transporter (DAT). Dysregulation of DAT and vesicular packaging mechanisms can increase cytosolic DA, leading to auto-oxidation and generation of ROS and neurotoxic quinones. In addition, inflammation-induced increased release and decreased reuptake of glutamate by glial cells, combined with quinolinic acid activation of $N$-Methyl-D-aspartic acid receptors, may lead to glutamate excitotoxicity that further contributes to oxidative stress and decreased DA availability. Finally, inflammatory cytokines may also decrease DA signaling by reducing DA D2 receptors. Figure adapted from Felger and Miller, 2012. 3-HAO, 3-hydroxyanthranilic acid oxygenase; AMPAR, 2-amino3-(5-methyl-3-oxo-1,2-oxazol-4-yl) propanoic acid receptor; D1, dopamine 1 receptor 1; D2, dopamine 2 receptor; DDC, dopamine decarboxylase; $\mathrm{KMO}$, kynurenine 3-monooxygenase; NMDAR, N-methyl-D-aspartic acid receptor; NO, nitric oxide; NOS, nitric oxide synthase; PAH, phenylalanine hydroxylase; ROS, reactive oxygen species; $\mathrm{TH}$, tyrosine hydroxylase.

and may serve as indirect biomarkers of DA synthetic capacity (Candito et al, 1994; Capuron et al, 2011; Hashimoto et al, 2004; Neurauter et al, 2008; Yokoyama et al, 2002). For example, a number of patient populations with increased inflammation, including patients with trauma, sepsis, cancer, and HIV, have been found to exhibit increased peripheral blood concentrations of phenylalanine (Hufner et al, 2015; Neurauter et al, 2008). Furthermore, increased phenylalanine concentrations in patients with cancer have been correlated with markers and mediators of inflammation including IL-6, IL-2 receptor, and soluble TNF receptor-2, as well as peripheral blood markers of oxidative stress (Neurauter et al, 2008). Moreover, in a study of healthy elderly persons with low-grade inflammation, peripheral blood concentrations of phenylalanine, tyrosine, and an increased phenylalanine/tyrosine ratio were associated with neuropsychiatric symptoms including anhedonia and altered sleep (Capuron et al, 2011).

Evidence of reduced $\mathrm{BH} 4$ activity has also been observed in IFN- $\alpha$-treated patients (Felger et al, 2013a; Zoller et al, 2012). For example, IFN- $\alpha$ administration was associated with increased peripheral blood phenylalanine/tyrosine ratio, which in turn correlated with decreased CSF DA and its major metabolite HVA (Felger et al, 2013a). Increased CSF IL-6 was also correlated with decreased BH4 in CSF of IFN$\alpha$-treated patients, and the phenylalanine/tyrosine ratio significantly correlated with IFN- $\alpha$-induced depressive symptoms (Felger et al, 2013a). These findings are consistent with decreased DA metabolites in the CSF of IFN- $\alpha$-treated patients and monkeys (Felger et al, 2007; Felger and Miller, 2012), and with reversal of IFN- $\alpha$-induced decreased release of DA by L-DOPA administered via reverse in vivo 
microdialysis in monkeys (Felger et al, 2015). Of note, during L-DOPA administration, no change was found in DOPAC/ $\mathrm{DA}$, which increases when DA is not properly packaged in synaptic vesicles and is subsequently metabolized via monoamine oxidase (Caudle et al, 2007).

Another mechanism by which cytokines may influence the basal ganglia and DA function is through the effects on glutamate neurotransmission. For example, there has been recent interest in the impact of cytokine stimulation of indoleamine 2,3-dioxygenase (IDO) and downstream kynurenine pathway metabolites on glutamate neurotransmission in the brain (Dantzer et al, 2011). Immune-mediated activation of IDO catabolizes tryptophan, the primary amino-acid precursor of serotonin, to kynurenine, which is converted to QUIN in the microglia (Dantzer and Walker, 2014; Schwarcz and Pellicciari, 2002). Increased concentrations of QUIN have been found in the plasma and CSF of IFN- $\alpha$-treated patients (Bonaccorso et al, 2002; Capuron et al, 2003a; Raison et al, 2010a), which correlated with depressive symptoms, as measured by MADRS (Raison et al, 2010a). In addition to increasing oxidative stress (Behan et al, 1999; Santamaria et al, 2003), the neurotoxic metabolite QUIN can also directly activate the N-methyl-daspartate (NMDA) receptor (Schwarcz et al, 2002; Tavares et al, 2005; Tavares et al, 2002). In addition, inflammatory cytokines can increase extracellular glutamate by decreasing excitatory amino-acid transporters, which are responsible for glutamate reuptake, and increasing glutamate release from astrocytes and activated microglia (Dantzer and Walker, 2014; Takaki et al, 2012; Tilleux and Hermans, 2007). This inflammationmediated increase in glutamate release and NMDA activation can lead to excitotoxicity in the brain (Guillemin, 2012; Guillemin et al, 2003), further increasing oxidative stress and potentially contributing to the effects on $\mathrm{BH} 4$ and DA synthesis (Felger and Miller, 2012; Najjar et al, 2013), as described above (Figure 2). In addition, increased xanthurenic acid, a metabolite of the kynurenine pathway upstream of QUIN, has been shown to directly attenuate $\mathrm{BH} 4$ biosynthesis by inhibition of sepiapterin reductase (Haruki et al, 2016).

Although these findings strongly suggest that inflammatory cytokines reduce DA availability through a deficiency in its precursors, some evidence exists indicating that cytokines may also target DA packaging, release, and reuptake mechanisms, as presented below.

\section{DA Packaging, Release, and Reuptake}

Synaptic DA is dependent on the vesicular monoamine transporter 2 (VMAT2) to package cytosolic DA into vesicles for release. There is some evidence that inflammatory cytokines and inflammation may negatively affect the expression and function of VMAT2 (Figure 2). For example, the inflammatory cytokines IL-1 and TNF were found to decrease expression of VMAT2 in rat enterochromaffin-like cells, whereas transforming growth factor- $\beta$, which is immunomodulatory and anti-inflammatory, increased VMAT2 expression (Kazumori et al, 2004). In addition, the anti-inflammatory compound, pituitary adenylate cyclase- activating polypeptide 38 , administered in vivo by subcutaneous minipump, was able to increase VMAT2 expression, reduce neuroinflammation, and oxidative stress, and protect against DA neurotoxicity following chronic methamphetamine exposure (Guillot et al, 2008).

Attention has been paid to the effects of cytokines and inflammatory signaling pathways on monoamine reuptake pumps, and particularly the serotonin transporter (Moron et al, 2003; Zhu et al, 2006; Zhu et al, 2005; Zhu et al, 2010). Both in vitro and in vivo data have established that the stimulation of p38 mitogen-activated protein kinase (MAPK), a primary signaling pathway activated by IFN- $\alpha$ and other cytokines, can increase the expression and function of the serotonin transporter, leading to increased serotonin reuptake ( $\mathrm{Zhu}$ et al, 2006; Zhu et al, 2005; Zhu et al, 2010). MAPK pathways have also been found to influence DAT. For example, DAT-expressing cells transfected with constitutively activate MAPK kinase (MEK) show increased DA reuptake (Vmax), whereas the treatment of rat striatal synaptosomes with MEK inhibitors decreased DA reuptake in a concentration- and time-dependent manner (Moron et al, 2003). Furthermore, subjects with neuropsychiatric disturbances as a result of HIV infection and subsequent neuroinflammation are thought to have increased expression of DAT (Ferris et al, 2008; Gelman et al, 2006). Therefore, reduced synaptic DA following chronic exposure to inflammatory cytokines may be mediated, in part, by increased DAT expression or function (Figure 2). However, no change in DAT binding, as measured by PET with 18F-labeled FECNT, was observed in monkeys exposed to chronic IFN- $\alpha$ (Felger et al, 2013c).

\section{DA Receptor Expression and Function}

Finally, inflammation and cytokines may affect DA signaling by reducing the expression or function of DA receptors. For instance, decreased D2 receptor binding using $\left[{ }^{11} \mathrm{C}\right]$ raclopride PET was found in the striatum of rhesus monkey chronically administered IFN- $\alpha$ (Felger et al, 2013c). Interestingly, decreased D2 receptor binding has been observed in the striatum of patients with obesity, who also exhibit both high levels of inflammatory markers and altered reward processing (Michaelides et al, 2012; Shelton and Miller, 2010; Steele et al, 2010; Timpson et al, 2011; Voon et al, 2015). In addition, decrease D2 receptors may have a feed forward effect on inflammation given that D2 signaling on astrocytes has been shown to inhibit inflammatory responses in the CNS (Shao et al, 2013), and DA receptors modulate anti- and pro-inflammatory responses of immune cells in the periphery (Pacheco et al, 2014).

\section{POTENTIAL THERAPEUTIC TARGETS FOR INFLAMMATION EFFECTS ON DA}

The data summarized herein demonstrate that inflammatory cytokines affect DA function and may contribute to the development of depressive symptoms relevant to reduced 
TABLE 2 Pharmacological Strategies that May Reverse Inflammation Effects on Dopamine to Improve Motivation and Motor Function

\begin{tabular}{|c|c|c|}
\hline Target & Compounds & Previous in studies/trials \\
\hline \multirow[t]{3}{*}{ Inflammation } & Cytokine antagonists & Increased motivation in MDD with high CRP (Raison et al, 2013b) \\
\hline & COX inhibitors & Mixed results in psychiatric patients (Köhler et al, 20 I4; Sommer et al, 20 I2) \\
\hline & Minocycline & Reduced negative symptoms in schizophrenia (Köhler et al, 20I4; Sommer et al, 2012) \\
\hline \multirow[t]{2}{*}{ DA synthesis } & L-DOPA & Increased motivation in PD (Czernecki et al, 2002) \\
\hline & $\mathrm{BH} 4$ & Case reports: improves depressive/motor symptoms (Pan et al, 201 I; Sato et al, 2014) \\
\hline \multirow[t]{2}{*}{ DA receptors } & D2 agonists & $\begin{array}{l}\text { Successful adjuvant in unipolar and bipolar depression (Cassano et al, 2004; Cusin et al, 20 I3; Fawcett et al, 20 l6; Franco-Chaves } \\
\text { et al, 2013) }\end{array}$ \\
\hline & $\begin{array}{l}\text { Adenosine A2A } \\
\text { antagonists }\end{array}$ & Reversal of IL-I $\beta$-induced decrease in effort-based motivation in rats (Nunes et al, 2014) \\
\hline $\begin{array}{l}\text { DA packaging } \\
\text { (VMAT) }\end{array}$ & 7,8-dihydroxyllavone & Increased VMAT2 and neuroprotection in a rodent model of PD (Jang et al, 20I0) \\
\hline
\end{tabular}

Abbreviations: BH4, tetrahydrobiopterin; COX, cyclooxygenase; CRP, C-reactive protein; D2, dopamine 2 receptor; DA, dopamine; IDO, indoleamine 2,3-dioxygenase; L-DOPA, L-3,4-dihydroxyphenylalanine; NMDA, N-methyl-D-aspartate; PD, Parkinson's disease; SAMe, S-adenosyl-methionine; SIV, simian immunodeficiency virus;

TrkB, tropomyosin receptor kinase B; VMAT, vesicular monoamine transporter.

motivation and motor activity in psychiatric patients with increased inflammation. Current antidepressant therapies are effective for many patients with MDD. However, up to $30 \%$ fail to achieve remission and even responders often exhibit significant residual symptoms that are consistent with those that are caused by the exposure to cytokines and inflammation, such as anhedonia, fatigue, and psychomotor retardation (Dunlop and Nemeroff, 2007; Nierenberg, 2015; Rush, 2007; Targum and Fava, 2011; Trivedi et al, 2008). Non-responsiveness of inflammation-related symptoms to standard antidepressant therapies has been exemplified in patients receiving IFN- $\alpha$ therapy who were treated with SSRIs. SSRIs alleviated cancer related or IFN- $\alpha$-induced anxiety and some depressive symptoms, but not those of fatigue or psychomotor retardation (Capuron et al, 2002a; Morrow et al, 2003; Raison et al, 2005b). In addition, patients with advanced cancer undergoing chemotherapy exhibit increased inflammation in association with fatigue that is not responsive to SSRIs (Ahles et al, 2002; Bower et al, 2002; Miller et al, 2008). Therefore, new conceptual frameworks are needed to treat these inflammation-associated symptoms (Capuron and Miller, 2004; Cattaneo et al, 2013; Raison et al, 2013a), which may respond to novel treatment strategies that target the DA system (Table 2).

Although classical stimulant medications that increase DA release and/or block DA reuptake increase motivation in rodent models (Randall et al, 2015; Yohn et al, 2015), they have demonstrated only limited efficacy in chronically treating fatigue and other DA-related symptoms in trials for patients with cancer and other medical illnesses that are associated with inflammation (Bruera et al, 2013; Butler et al, 2007; Escalante et al, 2014; Gong et al, 2014; Mar Fan et al, 2008; Moraska et al, 2010; Pucci et al, 2007; Ruddy et al, 2014; Stankoff et al, 2005; Sugawara et al, 2002).
As stimulants act to increase DA release and block DAT function to increase synaptic levels of available DA, these drugs may not provide long-term efficacy in the context of inflammation. As described in detail in the section 'Mechanisms of inflammation effects on dopamine synthesis and release' above, although some evidence exists that inflammation may reduce DA packaging and/or release, and decrease DA receptor signaling, the primary mechanism by which inflammation may impact DA transmission is by decreasing DA synthesis, which would lend to only a limited supply of available vesicular or cytosolic DA on which stimulants may act. Consistent with this idea, dietary depletion of DA precursors has been shown to decrease stimulant-induced striatal DA release in healthy humans and laboratory animals, as measured by $[11 \mathrm{C}]$ raclopride PET, and to decrease stimulant-induced locomotor behavior in laboratory animals (Dominic and Moore, 1969a, b; Le Masurier et al, 2004; Leyton et al, 2004). Therefore, consideration should be given to alternative strategies such as compounds that increase DA synthesis, packaging, or receptor signaling, or those that inhibit activation of the neuroactive metabolites of the kynurenine pathway and/or glutamate, which increase oxidative stress and may contribute to effects on DA transmission during inflammation. Of course strategies that inhibit inflammation and/or inflammatory cytokines themselves should also be considered and will be discussed.

\section{Therapies that Block Inflammation}

A number of recent studies have begun to test the potential of anti-inflammatory compounds as possible antidepressant therapies. Most studies to date have focused on compounds such as cyclooxygenase (COX) inhibitors or minocycline, 
which have relatively mild anti-inflammatory effects and numerous 'off target' effects that may confound data interpretation (Miller and Raison, 2015). A recent metaanalysis found a modest antidepressant effect of antiinflammatory agents in bipolar disorder (Rosenblat et al, 2016), yet trials using drugs that block oxidative stresswhich may have many sources other than inflammationwere also included in this analysis. Recent meta-analyses in depression and schizophrenia have also reported modest effect sizes indicating a benefit of COX inhibitors in reducing symptom severity, but with high heterogeneity across studies and mostly small sample sizes (Köhler et al, 2014; Sommer et al, 2012). A meta-analysis of four trials in schizophrenia found that the antibiotic minocycline was superior to placebo at reducing negative but not positive symptoms (Oya et al, 2014). It should be noted that the majority of studies included in the meta-analyses described above have not selected patients with increased inflammation nor have they measured peripheral inflammatory markers to establish antiinflammatory activity of the treatments. Interestingly, a recent study tested the efficacy of infliximab, a highly selective TNF antagonist, in treatment-resistant patients with MDD as a function of peripheral inflammation. Treatment with infliximab was associated with robust decreases in plasma CRP concentrations, as well as a strong antidepressant effect, but only in patients with elevated CRP at baseline (Raison et al, 2013b). Moreover, the greatest area of symptom improvement was related to motivation (Raison et al, 2013b), which is consistent with the hypothesis that blockade of inflammation may exert antidepressant properties through normalization of striatal DA function.

\section{Compounds that Improve DA Synthesis and Availability}

Considering the strong evidence presented above, indicating that inflammation can inhibit key components of DA synthesis, pharmacologic strategies that increase DA may effectively treat inflammation-related symptoms of anhedonia, fatigue, and psychomotor slowing. For instance, there are a number of compounds than can boost BH4 availability or activity, which may facility the capacity of PAH and TH to synthesize DA. These include the administration of $\mathrm{BH} 4$ itself (Douglas et al, 2013), which is currently approved in a synthetic form to treat phenylketonuria (Burton et al, 2010; Trefz et al, 2009; Utz et al, 2012), and folic acid or $S$-adenosyl-methionine (SAMe), which have a role in the synthesis and/or regeneration of BH4 (Felger and Miller, 2012; Shintaku, 2002; Stahl, 2007). Although the effects of BH4 administration on depressive and motor symptoms have not been reported outside of case reports (Pan et al, 2011; Sato et al, 2014), folic acid (in the form of L-methylfolate) and SAMe have demonstrated efficacy as adjuvants in depression trials (Ginsberg et al, 2011; Godfrey et al, 1990; Papakostas et al, 2010; Papakostas et al, 2012; Shelton et al, 2015). Interestingly, low serum folate has been associated with the increased risk of depression, as well as non-response to antidepressant treatment and an increased likelihood of depression relapse (Fava et al, 1997; Gilbody et al, 2007a; Gilbody et al, 2007b; Papakostas et al, 2004a; Papakostas et al, 2004b). Administration of L-methylfolate (marketed as Deplin and Zervalx) to patients with MDD has been shown to augment the efficacy of standard antidepressant therapy in two studies (Ginsberg et al, 2011; Godfrey et al, 1990); however, mixed results were reported in two parallel-sequential trials with only one trial finding efficacy over placebo (Papakostas et al, 2012). Treatment with SAMe adjunctive to SSRIs led to significantly higher rates of remission and $50 \%$ or greater decreases in depressive symptoms compared with placebo (Papakostas et al, 2010). Although SAMe produced a significantly greater reduction in depression scores compared with escitalopram at weeks 2-6 in a recent placebo-controlled trial in patients with MDD, no significant difference in response or remission rates was observed, possibly due to the increased variability over two study sites (Sarris et al, 2014). However, a subgroup analysis of this trial indicated that SAMe was effective in men but not women (Sarris et al, 2015). Of the reports described above, only one post hoc analysis of the two parallel-sequential adjuvant trials of L-methylfolate in patients with MDD (Papakostas et al, 2012) considered inflammatory markers. It was found that BMI $>30$ as well as concentrations of TNF, IL-8, CRP, and leptin over the median, alone or in combination with each other or with IL-6, predicted greater symptom improvement (Shelton et al, 2015). Therefore, strategies to augment $\mathrm{BH} 4$ activity exhibit potential for restoring DA function and treating symptoms of depression in patients with increased inflammation, yet specific effects on motivation or motor function remain to be determined. Replacement of DA with the precursor L-DOPA is known to improve motor function, but has also been shown to increase motivation in patients with PD (Czernecki et al, 2002). However, peripheral and CNS side effects may complicate the use of L-DOPA as a therapy in psychiatric patients (Castro-Garcia, 1997).

Finally, inhibition of the IDO pathway or glutamate may be an important target in reversing the impact of inflammation on basal ganglia DA function. The IDO antagonist, 1-methyl tryptophan, has been shown to abrogate the impact of LPS, as well as an attenuated form of Mycobacterium bovis, on depressive-like behavior (O'Connor et al, 2009a; O'Connor et al, 2008). Given that the neurotoxic effects of QUIN may be mediated by excessive glutamate excitotoxicity (Schwarcz et al, 2002; Tavares et al, 2005; Tavares et al, 2002), glutamate antagonists may be useful in preventing excitotoxic and oxidative effects on the highly sensitive DA neurons. Indeed, metabotropic glutamate receptor antagonists that modulate glutamate transmission in the basal ganglia have been successful in reducing DA cell loss in an animal model of PD (Masilamoni et al, 2011). Antagonism of the NMDA receptor with memantine in monkeys infected with simian immunodeficiency virus (SIV) also reversed the loss of DA in the striatum (Meisner et al, 2008) that occurs during SIV and HIV infection secondary to immune cell 
activation in the basal ganglia (Kumar et al, 2011; Scheller et al, 2005), in association with increased brain-derived neurotrophic factor (BDNF). Interestingly, inflammationinduced release of glutamate from glia cells (see above) may preferentially activate extrasynaptic NMDA receptors, which has been shown to decrease BDNF (Hardingham et al, 2002). Administration of the NMDA antagonist ketamine has potent antidepressant effects in depressed patients who are resistant to standard therapies and who often exhibit increased inflammation (aan het Rot et al, 2010; Price et al, 2009; Raison et al, 2013a). Indeed, a recent study in treatment-resistant depression found that patients who were most responsive to ketamine were those with the highest concentrations of serum IL-6 (Yang et al, 2015). Therefore, blockade of kynurenine pathways or modulation of glutamate neurotransmission may confer protection against inflammation and/or IDO-mediated effects on DA function to improve behavioral symptoms in patients with increased inflammation.

\section{Strategies to Facilitate DA Packaging and Release or DA Receptor Signaling}

In terms of targeting DA packaging and release, compounds that improve VMAT2 function could be considered for the treatment of cytokine-induced depression and fatigue. For instance, VMAT2 activity can be increased with the small molecule trkB agonist, 7,8-dihydroxyflavone, which was neuroprotective in a rodent model of PD (Jang et al, 2010). In addition to compounds that may increase DA availability and release, adenosine (A2A) receptor antagonists, which are thought to facilitate the activation of DA D2 receptors, are efficacious in reversing decreased effort-based sucrose consumption after DA depletion with tetrabenazine (a vesicular monoamine transporter inhibitor) and after peripheral administration of IL-1 $\beta$ in rats (Chen et al, 2001; Collins et al, 2010; Nunes et al, 2014; Xie et al, 2009; Yohn et al, 2015). The DA receptor agonist, pramipexole, has been shown to block endotoxin-induced degeneration of nigrostriatal DA cells (Iravani et al, 2008), and has also demonstrated the efficacy in unipolar and bipolar patients with treatment-resistant depression (Cassano et al, 2004; Cusin et al, 2013; Fawcett et al, 2016; Franco-Chaves et al, 2013).

\section{SUMMARY AND CONCLUSIONS}

In this review, we have attempted to outline the case for a molecular pathway linking precipitators of inflammation to reduced effort expenditure and impaired motor function via their effects on mesolimbic DA availability and signaling. Inflammation is increased in a significant proportion of patients with psychiatric illnesses, and has been associated with symptoms such as anhedonia, fatigue, and psychomotor retardation. Further, a large preclinical and clinical literature suggests that one of the proximal causes for these symptoms is alterations within DA-rich striatal circuitry. We have summarized ample data suggesting that disruptions of striatal DAergic tone can produce profound shifts in motivated behavior, and that increased inflammatory factors are capable of inducing such disruptions. Taken together, this suggests that inflammation may be associated with the origin of such symptoms, although this should not be taken to imply that all expressions of anhedonic symptoms are necessarily linked to inflammation. As stated by Miller and Raison (2015), 'no psychiatric disorder is an inflammatory disorder', and this may also be true at the level of specific symptoms. Rather, inflammation effects on DAergic systems may represent an etiopathophysiological subtype for rewardrelated symptoms that are common to multiple psychiatric disorders.

Importantly, the primary symptoms of this proposed subtype are often difficult to treat with standard therapies. Mechanistic evidence from humans and animals administered cytokines or inflammatory stimuli suggests that inflammatory cytokines may affect multiple aspects of DA neurotransmission, leading to decreased synthesis, DA receptor signaling, and/or impaired packaging or release, all of which may interact to a greater or lesser extent to reduce DA function. Multiple potential pharmacological treatment strategies exist, yet future studies are needed to identify precise targets for reversing inflammation effects on brain DA. Moving forward, studies using experimental strategies to block inflammation or reverse its effects on DA and reward circuitry will further validate the existence of an inflammatory subtype, and guide development of novel therapies to treat DA-relevant behavioral symptoms in psychiatric patients with increased inflammation.

\section{FUNDING AND DISCLOSURE}

In the past 3 years, JCF has consulted for Proctor and Gamble and Pfizer, and MTT has consulted for the Boston Consulting Group, Avanir Pharmaceuticals, and NeuroCogTrials. No funding or sponsorship was provided by these companies for the current work, and all views expressed sherein are solely those of authors. This work was supported by funds from the National Institute of Mental Health to JCF (R21MH106904) and MTT (R00MH102355 and R01MH108605), the Dana Foundation to JCF (CADF49143), and by the Brain and Behavioral Research Foundation to JCF (BBRF22296). In addition, the study was supported in part by PHS Grants UL1TR000454 from the Clinical and Translational Science Award program, by Winship Cancer Institute ACS IRG \#126815-IRG-14-188-01-IRG from the American Cancer Society, and by the NIH/NCI under award number P30CA138292. The authors declare no conflict of interest.

\section{REFERENCES}

aan het Rot M, Collins KA, Murrough JW, Perez AM, Reich DL, Charney DS et al (2010). Safety and efficacy of repeated-dose intravenous ketamine for treatmentresistant depression. Biol Psychiatry 67: 139-145. 
Abi-Dargham A, Gil R, Krystal J, Baldwin RM, Seibyl JP, Bowers M et al (1998). Increased striatal dopamine transmission in schizophrenia: confirmation in a second cohort. Am J Psychiatry 155: 761-767.

Ahles TA, Saykin AJ, Furstenberg CT, Cole B, Mott LA, Skalla K et al (2002). Neuropsychologic impact of standard-dose systemic chemotherapy in long-term survivors of breast cancer and lymphoma. J Clin Oncol 20: 485-493.

Ananth J, Djenderdjian A, Shamasunder P, Costa J, Herrera J, Sramek J (1991). Negative symptoms: psychopathological models. J Psychiatry Neurosci 16: 12-18.

Arrondo G, Segarra N, Metastasio A, Ziauddeen H, Spencer J, Reinders NR et al (2015). Reduction in ventral striatal activity when anticipating a reward in depression and schizophrenia: a replicated cross-diagnostic finding. Fron Psychol 6: 1280.

Bamne M, Wood J, Chowdari K, Watson AM, Celik C, Mansour H et al (2012). Evaluation of HLA polymorphisms in relation to schizophrenia risk and infectious exposure. Schizophr Bull 38: 1149-1154.

Banks WA, Erickson MA (2010). The blood-brain barrier and immune function and dysfunction. Neurobiol Dis 37: 26-32.

Banks WA, Farr SA, Morley JE (2002). Entry of blood-borne cytokines into the central nervous system: effects on cognitive processes. Neuroimmunomodulation 10: 319-327.

Banks WA, Kastin AJ, Broadwell RD (1995). Passage of cytokines across the bloodbrain barrier. Neuroimmunomodulation 2: 241-248.

Barbosa IG, Bauer ME, Machado-Vieira R, Teixeira AL (2014). Cytokines in bipolar disorder: paving the way for neuroprogression. Neural Plast 2014: 360481.

Barch DM, Treadway MT, Schoen N (2014). Effort, anhedonia, and function in schizophrenia: Reduced effort allocation predicts amotivation and functional impairment. J Abnorm Psychol 123: 387.

Barrot M, Marinelli M, Abrous DN, Rouge-Pont F, Le Moal M, Piazza PV (2000). The dopaminergic hyper-responsiveness of the shell of the nucleus accumbens is hormone-dependent. Eur J Neurosci 12: 973-979.

Behan WM, McDonald M, Darlington LG, Stone TW (1999). Oxidative stress as a mechanism for quinolinic acid-induced hippocampal damage: protection by melatonin and deprenyl. Br J Pharmacol 128: 1754-1760.

Beierholm U, Guitart-Masip M, Economides M, Chowdhury R, Duzel E, Dolan R et al (2013). Dopamine modulates reward-related vigor. Neuropsychopharmacology 38: 1495-1503.

Bennabi D, Vandel P, Papaxanthis C, Pozzo T, Haffen E (2013). Psychomotor retardation in depression: a systematic review of diagnostic, pathophysiologic, and therapeutic implications. Biomed Res Int 2013: 158746.

Berk M, Williams LJ, Jacka FN, O'Neil A, Pasco JA, Moylan S et al (2013). So depression is an inflammatory disease, but where does the inflammation come from? BMC Med 11: 200.

Bernacer J, Corlett PR, Ramachandra P, McFarlane B, Turner DC, Clark L et al (2013). Methamphetamine-induced disruption of frontostriatal reward learning signals: relation to psychotic symptoms. Am J Psychiatry 170: 1326-1334.

Bernheimer H, Birkmayer W, Hornykiewicz O, Jellinger K, Seitelberger F (1973). Brain dopamine and the syndromes of Parkinson and Huntington Clinical, morphological and neurochemical correlations. J Neurol Sci 20: 415-455.

Berridge KC (2007). The debate over dopamine's role in reward: the case for incentive salience. Psychopharmacology (Berl) 191: 391-431.

Berridge KC, Kringelbach ML (2008). Affective neuroscience of pleasure: reward in humans and animals. Psychopharmacology (Berl) 199: 457-480.

Berridge KC, Kringelbach ML (2013). Neuroscience of affect: brain mechanisms of pleasure and displeasure. Curr Opin Neurobiol 23: 294-303.

Bjork JM, Grant SJ, Chen G, Hommer DW (2014). Dietary tyrosine/phenylalanine depletion effects on behavioral and brain signatures of human motivational processing. Neuropsychopharmacology 39: 595-604.

Blalock JE, Smith EM (1981). Human leukocyte interferon (HulFN-alpha): potent endorphin-like opioid activity. Biochem Biophys Res Commun 101: 472-478.

Bloomfield PS, Selvaraj S, Veronese M, Rizzo G, Bertoldo A, Owen DR et al (2015). Microglial activity in people at ultra high risk of psychosis and in schizophrenia: an [11C] PBR28 PET brain imaging study. Am J Psychiatry 173: 44-52.

Bluthe RM, Walter V, Parnet P, Laye S, Lestage J, Verrier D et al (1994). Lipopolysaccharide induces sickness behaviour in rats by a vagal mediated mechanism. C R Acad Sci III 317: 499-503

Bonaccorso S, Marino V, Puzella A, Pasquini M, Biondi M, Artini M et al (2002). Increased depressive ratings in patients with hepatitis $C$ receiving interferonalpha-based immunotherapy are related to interferon-alpha-induced changes in the serotonergic system. J Clin Psychopharmacol 22: 86-90.

Bonsall DR, Kim H, Tocci C, Ndiaye A, Petronzio A, McKay-Corkum G et al (2015). Suppression of locomotor activity in female C57BI/6J mice treated with interleukin-1beta: investigating a method for the study of fatigue in laboratory animals. PLoS One 10: e0140678.
Bosker FJ, Hartman CA, Nolte IM, Prins BP, Terpstra P, Posthuma D et al (2011). Poor replication of candidate genes for major depressive disorder using genomewide association data. Mol Psychiatry 16: 516-532.

Bower JE, Ganz PA, Aziz N, Fahey JL (2002). Fatigue and proinflammatory cytokine activity in breast cancer survivors. Psychosom Med 64: 604-611.

Bragulat V, Paillere-Martinot ML, Artiges E, Frouin V, Poline JB, Martinot JL (2007). Dopaminergic function in depressed patients with affective flattening or with impulsivity: [18Ffluoro-L-dopa positron emission tomography study with voxelbased analysis. Psychiatry Res 154: 115-124.

Brambilla P, Bellani M, Isola M, Bergami A, Marinelli V, Dusi N et al (2014). Increased M1/decreased M2 signature and signs of Th1/Th2 shift in chronic patients with bipolar disorder, but not in those with schizophrenia. Transl Psychiatry 4: e406.

Bruera E, Yennurajalingam S, Palmer JL, Perez-Cruz PE, Frisbee-Hume S, Allo JA et al (2013). Methylphenidate and/or a nursing telephone intervention for fatigue in patients with advanced cancer: a randomized, placebo-controlled, phase II trial. J Clin Oncol 31: 2421-2427.

Bryant PA, Trinder J, Curtis N (2004). Sick and tired: Does sleep have a vital role in the immune system? Nat Rev Immunol 4: 457-467.

Brydon L, Harrison NA, Walker C, Steptoe A, Critchley HD (2008). Peripheral inflammation is associated with altered substantia nigra activity and psychomotor slowing in humans. Biol Psychiatry 63: 1022-1029.

Bufalino C, Hepgul N, Aguglia E, Pariante CM (2012). The role of immune genes in the association between depression and inflammation: A review of recent clinical studies. Brain Behav Immun 31: 31-47.

Burton BK, Bausell H, Katz R, Laduca H, Sullivan C (2010). Sapropterin therapy increases stability of blood phenylalanine levels in patients with $\mathrm{BH} 4$-responsive phenylketonuria (PKU). Mol Genet Metab 101: 110-114.

Butler JM Jr., Case LD, Atkins J, Frizzell B, Sanders G, Griffin P et al (2007). A phase III, double-blind, placebo-controlled prospective randomized clinical trial of d-threo-methylphenidate $\mathrm{HCl}$ in brain tumor patients receiving radiation therapy. Int J Radiat Oncol Biol Phys 69: 1496-1501.

Buyukdura JS, McClintock SM, Croarkin PE (2011). Psychomotor retardation in depression: biological underpinnings, measurement, and treatment. Prog Neuropsychopharmacol Biol Psychiatry 35: 395-409.

Bylsma LM, Morris BH, Rottenberg J (2008). A meta-analysis of emotional reactivity in major depressive disorder. Clin Psychol Rev 28: 676-691.

Cagnin A, Kassiou M, Meikle SR, Banati RB (2007). Positron emission tomography imaging of neuroinflammation. Neurotherapeutics 4: 443-452.

Caligiuri MP, Ellwanger J (2000). Motor and cognitive aspects of motor retardation in depression. J Affect Disord 57: 83-93.

Candito M, Nagatsu T, Chambon P, Chatel M (1994). High-performance liquid chromatographic measurement of cerebrospinal fluid tetrahydrobiopterin, neopterin, homovanillic acid and 5-hydroxindoleacetic acid in neurological diseases. J Chromatogr B Biomed App/ 657: 61-66.

Cannon CM, Palmiter RD (2003). Reward without dopamine. J Neurosci 23: 10827-10831.

Cannon DM, Klaver JM, Peck SA, Rallis-Voak D, Erickson K, Drevets WC (2009). Dopamine type-1 receptor binding in major depressive disorder assessed using positron emission tomography and [11C]NNC-112. Neuropsychopharmacology 34: 1277-1287.

Capuron L, Gumnick JF, Musselman DL, Lawson DH, Reemsnyder A, Nemeroff CB et al (2002a). Neurobehavioral effects of interferon-alpha in cancer patients: phenomenology and paroxetine responsiveness of symptom dimensions. Neuropsychopharmacology 26: 643-652.

Capuron L, Hauser P, Hinze-Selch D, Miller AH, Neveu PJ (2002b). Treatment of cytokine-induced depression. Brain Behav Immun 16: 575-580.

Capuron L, Miller AH (2004). Cytokines and psychopathology: lessons from interferon-alpha. Biol Psychiatry 56: 819-824.

Capuron L, Neurauter G, Musselman DL, Lawson DH, Nemeroff CB, Fuchs D et al (2003a). Interferon-alpha-induced changes in tryptophan metabolism. relationship to depression and paroxetine treatment. Biol Psychiatry 54: 906-914.

Capuron L, Pagnoni G, Demetrashvili MF, Lawson DH, Fornwalt FB, Woolwine B et al (2007). Basal ganglia hypermetabolism and symptoms of fatigue during interferon-alpha therapy. Neuropsychopharmacology 32: 2384-2392.

Capuron L, Pagnoni G, Drake DF, Woolwine BJ, Spivey JR, Crowe RJ et al (2012). Dopaminergic mechanisms of reduced basal ganglia responses to hedonic reward during interferon alfa administration. Arch Gen Psychiatry 69: 1044-1053.

Capuron L, Raison CL, Musselman DL, Lawson DH, Nemeroff CB, Miller AH (2003b). Association of exaggerated HPA axis response to the initial injection of interferon-alpha with development of depression during interferon-alpha therapy. Am J Psychiatry 160: 1342-1345.

Capuron L, Schroecksnadel S, Feart C, Aubert A, Higueret D, Barberger-Gateau P et al (2011). Chronic low-grade inflammation in elderly persons is associated with altered tryptophan and tyrosine metabolism: role in neuropsychiatric symptoms. Biol Psychiatry 70: 175-182. 
Cassano P, Lattanzi L, Soldani F, Navari S, Battistini G, Gemignani A et al (2004). Pramipexole in treatment-resistant depression: an extended follow-up. Depress Anxiety 20: 131-138.

Castro-Garcia A (1997). [Psychiatric complications of L-dopa: physiopathology and treatment]. Rev Neurol 25(Suppl 2): S157-S162.

Cattaneo A, Gennarelli M, Uher R, Breen G, Farmer A, Aitchison KJ et al (2013). Candidate genes expression profile associated with antidepressants response in the GENDEP study: differentiating between baseline 'predictors' and longitudinal 'targets'. Neuropsychopharmacology 38: 377-385.

Caudle WM, Richardson JR, Wang MZ, Taylor TN, Guillot TS, McCormack AL et al (2007). Reduced vesicular storage of dopamine causes progressive nigrostriatal neurodegeneration. J Neurosci 27: 8138-8148.

Chase KA, Rosen C, Gin H, Bjorkquist O, Feiner B, Marvin R et al (2015). Metabolic and inflammatory genes in schizophrenia. Psychiatry Res 225: 208-211.

Chaudhury D, Walsh JJ, Friedman AK, Juarez B, Ku SM, Koo JW et al (2013). Rapid regulation of depression-related behaviours by control of midbrain dopamine neurons. Nature 493: 532-536.

Chen JF, Moratalla R, Impagnatiello F, Grandy DK, Cuellar B, Rubinstein M et al (2001). The role of the $D(2)$ dopamine receptor $(D(2) R)$ in $A(2 A)$ adenosine receptor $(A(2 A) R)$-mediated behavioral and cellular responses as revealed by $A(2 A)$ and $D$ (2) receptor knockout mice. Proc Natl Acad Sci USA 98: 1970-1975.

Clery-Melin ML, Schmidt L, Lafargue G, Baup N, Fossati P, Pessiglione M (2011). Why don't you try harder? An investigation of effort production in major depression. PLOS ONE 6: e23178.

Coffeen U, Ortega-Legaspi JM, de Gortari P, Simon-Arceo K, Jaimes O, Amaya MI et al (2010). Inflammatory nociception diminishes dopamine release and increases dopamine D2 receptor mRNA in the rat's insular cortex. Mol Pain 6: 75.

Collins AG, Frank MJ (2016). Surprise! Dopamine signals mix action, value and error. Nat Neurosci 19: 3-5.

Collins LE, Galtieri DJ, Collins P, Jones SK, Port RG, Paul NE et al (2010). Interactions between adenosine and dopamine receptor antagonists with different selectivity profiles: effects on locomotor activity. Behav Brain Res 211: 148-155.

Cooper AJ, Smillie LD, Jackson CJ (2008). A trait conceptualization of rewardreactivity. J Individ Differ 29: 168-180.

Correa M, Carlson BB, Wisniecki A, Salamone JD (2002). Nucleus accumbens dopamine and work requirements on interval schedules. Behav Brain Res 137: 179-187.

Cunnington C, Channon KM (2010). Tetrahydrobiopterin: pleiotropic roles in cardiovascular pathophysiology. Heart 96: 1872-1877.

Cusin C, lovieno N, losifescu DV, Nierenberg AA, Fava M, Rush AJ et al (2013). A randomized, double-blind, placebo-controlled trial of pramipexole augmentation in treatment-resistant major depressive disorder. J Clin Psychiatry 74: e636-e641.

Czernecki V, Pillon B, Houeto JL, Pochon JB, Levy R, Dubois B (2002). Motivation, reward, and Parkinson's disease: influence of dopatherapy. Neuropsychologia 40: 2257-2267.

D'Ardenne KMS, Nystrom LE, Cohen JD (2008). BOLD responses reflecting dopaminergic signals in the human ventral tegmental area. Science 5867: 1264-1267.

D'Haenen HA, Bossuyt A (1994). Dopamine D2 receptors in depression measured with single photon emission computed tomography. Biol Psychiatry 35: $128-132$.

D'Mello C, Le T, Swain MG (2009). Cerebral microglia recruit monocytes into the brain in response to tumor necrosis factoralpha signaling during peripheral organ inflammation. J Neurosci 29: 2089-2102.

D'Mello C, Ronaghan N, Zaheer R, Dicay M, Le T, MacNaughton WK et al (2015). Probiotics improve inflammation-associated sickness behavior by altering communication between the peripheral immune system and the brain. $J$ Neurosci 35: $10821-10830$.

Danese A, Caspi A, Williams B, Ambler A, Sugden K, Mika J et al (2011). Biological embedding of stress through inflammation processes in childhood. Mol Psychiatry 16: 244-246.

Danese A, Moffitt TE, Pariante CM, Ambler A, Poulton R, Caspi A (2008). Elevated inflammation levels in depressed adults with a history of childhood maltreatment. Arch Gen Psychiatry 65: 409-415.

Danese A, Pariante CM, Caspi A, Taylor A, Poulton R (2007). Childhood maltreatment predicts adult inflammation in a life-course study. Proc Natl Acad Sci USA 104: 1319-1324.

Dantzer R, O'Connor JC, Lawson MA, Kelley KW (2011). Inflammation-associated depression: from serotonin to kynurenine. Psychoneuroendocrinology 36: 426-436.

Dantzer R, Walker AK (2014). Is there a role for glutamate-mediated excitotoxicity in inflammation-induced depression? J Neural Transm Nienna) 121: 925-932.

de La Serre CB, Ellis CL, Lee J, Hartman AL, Rutledge JC, Raybould HE (2010). Propensity to high-fat diet-induced obesity in rats is associated with changes in the gut microbiota and gut inflammation. Am J Physiol Gastrointest Liver Physiol 299: G440-G448.

de Wit H, Uhlenhuth EH, Johanson CE (1986). Individual differences in the reinforcing and subjective effects of amphetamine and diazepam. Drug Alcohol Depend 16: 341-360.

Dichter GS, Felder JN, Petty C, Bizzell J, Ernst M, Smoski MJ (2009). The effects of psychotherapy on neural responses to rewards in major depression. Biol Psychiatry 66: 886-897.

Dichter GS, Smoski MJ, Kampov-Polevoy AB, Gallop R, Garbutt JC (2010). Unipolar depression does not moderate responses to the Sweet Taste Test. Depression Anxiety 27: 859-863.

Diekhof EK, Kaps L, Falkai P, Gruber O (2012). The role of the human ventral striatum and the medial orbitofrontal cortex in the representation of reward magnitude - an activation likelihood estimation meta-analysis of neuroimaging studies of passive reward expectancy and outcome processing. Neuropsychologia 50: 1252-1266.

Dinarello CA (2004). Infection, fever, and exogenous and endogenous pyrogens: some concepts have changed. J Endotoxin Res 10: 201-222.

Dominic JA, Moore KE (1969a). Acute effects of alpha-methyltyrosine on brain catecholamine levels and on spontaneous and amphetamine-stimulated motor activity in mice. Arch Int Pharmacodyn Ther 178: 166-176.

Dominic JA, Moore KE (1969b). Supersensitivity to the central stimulant actions of adrenergic drugs following discontinuation of a chronic diet of alphamethyltyrosine. Psychopharmacologia 15: 96-101.

Donnelly S (1998). Patient management strategies for interferon alfa-2b as adjuvant therapy of high-risk melanoma. Oncol Nurs Forum 25: 921-927.

Douglas TD, Jinnah HA, Bernhard D, Singh RH (2013). The effects of sapropterin on urinary monoamine metabolites in phenylketonuria. Mol Genet Metab 109: 243-250.

Dowell NG, Cooper EA, Tibble J, Voon V, Critchley HD, Cercignani M et al (2016). Acute changes in striatal microstructure predict the development of interferonalpha induced fatigue. Biol Psychiatry 79: 320-328.

Dowlati Y, Herrmann N, Swardfager W, Liu H, Sham L, Reim EK et al (2010). A metaanalysis of cytokines in major depression. Biol Psychiatry 67: 446-457.

Drago A, Crisafulli C, Calabro M, Serretti A (2015). Enrichment pathway analysis. The inflammatory genetic background in bipolar disorder. $J$ Affect Disord 179: 88-94.

Drevets WC, Gautier C, Price JC, Kupfer DJ, Kinahan PE, Grace AA et al (2001). Amphetamine-induced dopamine release in human ventral striatum correlates with euphoria. Biol Psychiatry 49: 81-96.

Dunlop BW, Nemeroff CB (2007). The role of dopamine in the pathophysiology of depression. Arch Gen Psychiatry 64: 327-337.

Eidelberg D, Moeller JR, Dhawan V, Spetsieris P, Takikawa S, Ishikawa T et al (1994). The metabolic topography of parkinsonism. J Cereb Blood Flow Metab 14: 783-801.

Eisenberger NI, Berkman ET, Inagaki TK, Rameson LT, Mashal NM, Irwin MR (2010). Inflammation-induced anhedonia: endotoxin reduces ventral striatum responses to reward. Biol Psychiatry 68: 748-754.

Ericsson A, Kovacs KJ, Sawchenko PE (1994). A functional anatomical analysis of central pathways subserving the effects of interleukin-1 on stress-related neuroendocrine neurons. J Neurosci 14: 897-913.

Escalante CP, Meyers C, Reuben JM, Wang X, Qiao W, Manzullo E et al (2014). A randomized, double-blind, 2-period, placebo-controlled crossover trial of a sustained-release methylphenidate in the treatment of fatigue in cancer patients. Cancer J 20: 8-14.

Evans DL, Staab JP, Petitto JM, Morrison MF, Szuba MP, Ward HE et al (1999). Depression in the medical setting: biopsychological interactions and treatment considerations. J Clin Psychiatry 60(Suppl 4): 40-55.

Fahey B, Hickey B, Kelleher D, O'Dwyer AM, O'Mara SM (2007). The widely-used anti-viral drug interferon-alpha induces depressive- and anxiogenic-like effects in healthy rats. Behav Brain Res 182: 80-87.

Fava M, Borus JS, Alpert JE, Nierenberg AA, Rosenbaum JF, Bottiglieri T (1997). Folate, vitamin B12, and homocysteine in major depressive disorder. Am J Psychiatry 154: 426-428.

Fawcett J, Rush AJ, Vukelich J, Diaz SH, Dunklee L, Romo P et al (2016). Clinical experience with high-dosage pramipexole in patients with treatment-resistant depressive episodes in unipolar and bipolar depression. Am J Psychiatry 173: 107-111.

Feighner JP, Robins E, Guze SB, Woodruff RA, Winokur G, Munoz R (1972). Diagnostic criteria for use in psychiatric research. Arch Gen Psychiatry 26: 57-63.

Felger JC, Alagbe O, Hu F, Mook D, Freeman AA, Sanchez MM et al (2007). Effects of interferon-alpha on rhesus monkeys: a nonhuman primate model of cytokineinduced depression. Biol Psychiatry 62: 1324-1333.

Felger JC, Hernandez CR, Miller AH (2015). Levodopa reverses cytokine-induced reductions in striatal dopamine release. Int $J$ Neuropsychopharmacol 18: 1-5. 
Felger JC, Li L, Marvar PJ, Woolwine BJ, Harrison DG, Raison CL et al (2013a). Tyrosine metabolism during interferon-alpha administration: association with fatigue and CSF dopamine concentrations. Brain Behav Immun 31: 153-160.

Felger JC, Li Z, Haroon E, Woolwine BJ, Jung MY, Hu X et al (2016). Inflammation is associated with decreased functional connectivity within corticostriatal reward circuitry in depression. Mol Psychiatry (in press).

Felger JC, Lotrich FE (2013b). Inflammatory cytokines in depression: Neurobiological mechanisms and therapeutic implications. Neuroscience 246: 199-229.

Felger JC, Miller AH (2012). Cytokine effects on the basal ganglia and dopamine function: the subcortical source of inflammatory malaise. Front Neuroendocrinol 33: 315-327

Felger JC, Mun J, Kimmel HL, Nye JA, Drake DF, Hernandez CR et al (2013c). Chronic interferon-alpha decreases dopamine 2 receptor binding and striatal dopamine release in association with anhedonia-like behavior in nonhuman primates. Neuropsychopharmacology 38: 2179-2187.

Ferenczi EA, Zalocusky KA, Liston C, Grosenick L, Warden MR, Amatya D et al (2016). Prefrontal cortical regulation of brainwide circuit dynamics and rewardrelated behavior. Science 351: aac9698.

Ferris MJ, Mactutus CF, Booze RM (2008). Neurotoxic profiles of HIV, psychostimulant drugs of abuse, and their concerted effect on the brain: current status of dopamine system vulnerability in NeuroAIDS. Neurosci Biobehav Rev 32: 883-909.

Fervaha G, Graff-Guerrero A, Zakzanis KK, Foussias G, Agid O, Remington G (2013). Incentive motivation deficits in schizophrenia reflect effort computation impairments during cost-benefit decision-making. J Psychiatr Res 47: 1590-1596.

Fillman SG, Sinclair D, Fung SJ, Webster MJ, Shannon Weickert C (2014). Markers of inflammation and stress distinguish subsets of individuals with schizophrenia and bipolar disorder. Transl Psychiatry 4: e365.

Forbes EE, Hariri AR, Martin SL, Silk JS, Moyles DL, Fisher PM et al (2009). Altered striatal activation predicting real-world positive affect in adolescent major depressive disorder. Am J Psychiatry 166: 64-73.

Franco-Chaves JA, Mateus CF, Luckenbaugh DA, Martinez PE, Mallinger AG, Zarate CA Jr. (2013). Combining a dopamine agonist and selective serotonin reuptake inhibitor for the treatment of depression: a double-blind, randomized pilot study. J Affect Disord 149: 319-325.

Frank MJ, O'Reilly RC (2006). A mechanistic account of striatal dopamine function in human cognition: psychopharmacological studies with cabergoline and haloperidol. Behav Neurosci 120: 497.

Frank MJ, Seeberger LC, O'Reilly RC (2004). By carrot or by stick: cognitive reinforcement learning in parkinsonism. Science 306: 1940-1943.

Frenois F, Moreau M, O'Connor J, Lawson M, Micon C, Lestage J et al (2007). Lipopolysaccharide induces delayed FosB/DeltaFosB immunostaining within the mouse extended amygdala, hippocampus and hypothalamus, that parallel the expression of depressive-like behavior. Psychoneuroendocrinology 32: 516-531.

Fusar-Poli P, Meyer-Lindenberg A (2012). Striatal presynaptic dopamine in schizophrenia, Part II: meta-analysis of [18F/11C]-DOPA PET studies. Schizophr Bull 39: 33-42.

Gard DE, Gard MG, Kring AM, John OP (2006). Anticipatory and consummatory components of the experience of pleasure: a scale development study. $J$ Res Personality 40: 1086-1102.

Gard DE, Sanchez AH, Cooper K, Fisher M, Garrett C, Vinogradov S (2014). Do people with schizophrenia have difficulty anticipating pleasure, engaging in effortful behavior, or both? J Abnorm Psychol 123: 771-782.

Garver DL, Tamas RL, Holcomb JA (2003). Elevated interleukin-6 in the cerebrospinal fluid of a previously delineated schizophrenia subtype. Neuropsychopharmacology 28: 1515-1520.

Gelman BB, Spencer JA, Holzer CE 3rd, Soukup VM (2006). Abnormal striatal dopaminergic synapses in National NeuroAIDS Tissue Consortium subjects with HIV encephalitis. J Neuroimmune Pharmacol 1: 410-420.

Gilbody S, Lewis S, Lightfoot T (2007a). Methylenetetrahydrofolate reductase (MTHFR) genetic polymorphisms and psychiatric disorders: a HuGE review. Am J Epidemiol 165: 1-13.

Gilbody S, Lightfoot T, Sheldon T (2007b). Is low folate a risk factor for depression? A meta-analysis and exploration of heterogeneity. $J$ Epidemiol Community Health 61: 631-637.

Ginsberg LD, Oubre AY, Daoud YA (2011). L-methylfolate Plus SSRI or SNRI from treatment initiation compared to SSRI or SNRI monotherapy in a major depressive episode. Innov Clin Neurosci 8: 19-28.

Godfrey PS, Toone BK, Carney MW, Flynn TG, Bottiglieri T, Laundy M et al (1990). Enhancement of recovery from psychiatric illness by methylfolate. Lancet $\mathbf{3 3 6}$ 392-395.

Gold JM, Strauss GP, Waltz JA, Robinson BM, Brown JK, Frank MJ (2013). Negative symptoms of schizophrenia are associated with abnormal effort-cost computations. Biol Psychiatry 74: 130-136.
Gold JM, Waltz JA, Prentice KJ, Morris SE, Heerey EA (2008). Reward processing in schizophrenia: a deficit in the representation of value. Schizophr Bull 34: 835-847. Goldsmith DR, Haroon E, Woolwine BJ, Jung MY, Wommack EC, Harvey PD et al (2016a). Inflammatory markers are associated with decreased psychomotor speed in patients with major depressive disorder. Brain Behav Immun 56: 281-288.

Goldsmith DR, Rapaport MH, Miller BJ (2016b). A meta-analysis of blood cytokine network alterations in psychiatric patients: comparisons between schizophrenia, bipolar disorder and depression. Mol Psychiatry (in press).

Gong S, Sheng P, Jin H, He H, Qi E, Chen W et al (2014). Effect of methylphenidate in patients with cancer-related fatigue: a systematic review and meta-analysis. PLoS One 9: e84391.

Gotlib IH, Hamilton JP, Cooney RE, Singh MK, Henry ML, Joormann J (2010). Neural processing of reward and loss in girls at risk for major depression. Arch Gen Psychiatry 67: 380-387.

Gradin VB, Kumar P, Waiter G, Ahearn T, Stickle C, Milders M et al (2011). Expected value and prediction error abnormalities in depression and schizophrenia. Brain 134(Pt 6): 1751-1764.

Greenberg T, Chase HW, Almeida JR, Stiffler R, Zevallos CR, Aslam HA et al (2015). Moderation of the relationship between reward expectancy and prediction errorrelated ventral striatal reactivity by anhedonia in unmedicated major depressive disorder: findings from the EMBARC study. Am J Psychiatry 172: 881-891.

Guillemin GJ (2012). Quinolinic acid: neurotoxicity. FEBS J 279: 1355.

Guillemin GJ, Croitoru-Lamoury J, Dormont D, Armati PJ, Brew BJ (2003). Quinolinic acid upregulates chemokine production and chemokine receptor expression in astrocytes. Glia 41: 371-381.

Guillot TS, Richardson JR, Wang MZ, Li YJ, Taylor TN, Ciliax BJ et al (2008). PACAP38 increases vesicular monoamine transporter 2 (VMAT2) expression and attenuates methamphetamine toxicity. Neuropeptides 42: 423-434.

Guo J, Zhang W, Zhang L, Ding H, Zhang J, Song C et al (2016). Probable involvement of $\mathrm{p} 11$ with interferon alpha induced depression. Sci Rep 6: 17029.

Guo S, Chen S, Zhang Q, Wang Y, Xu K, Zheng X (2014). Optogenetic activation of the excitatory neurons expressing CaMKllalpha in the ventral tegmental area upregulates the locomotor activity of free behaving rats. Biomed Res Int 2014: 687469.

Haber SN, Knutson B (2010). The reward circuit: linking primate anatomy and human imaging. Neuropsychopharmacology 35: 4-26.

Hamid AA, Pettibone JR, Mabrouk OS, Hetrick VL, Schmidt R, Vander Weele CM et al (2016). Mesolimbic dopamine signals the value of work. Nature neuroscience 19: $117-126$.

Hamilton JP, Chen G, Thomason ME, Schwartz ME, Gotlib IH (2011). Investigating neural primacy in major depressive disorder: multivariate Granger causality analysis of resting-state fMRI time-series data. Mol Psychiatry 16: 763-772.

Hannestad J, Gallezot J-D, Schafbauer T, Lim K, Kloczynski T, Morris ED et al (2012a). Endotoxin-induced systemic inflammation activates microglia:[11 C] PBR28 positron emission tomography in nonhuman primates. Neuroimage 63: 232-239.

Hannestad J, Gallezot JD, Schafbauer T, Lim K, Kloczynski T, Morris ED et al (2012b). Endotoxin-induced systemic inflammation activates microglia: [(11)C] PBR28 positron emission tomography in nonhuman primates. Neuroimage 63: 232-239.

Hardingham GE, Fukunaga Y, Bading H (2002). Extrasynaptic NMDARs oppose synaptic NMDARs by triggering CREB shut-off and cell death pathways. Nat Neurosci 5: 405-414.

Hare TA, O'Doherty J, Camerer CF, Schultz W, Rangel A (2008). Dissociating the role of the orbitofrontal cortex and the striatum in the computation of goal values and prediction errors. J Neurosci 28: 5623-5630.

Haroon E, Fleischer CC, Felger JC, Chen X, Woolwine BJ, Patel T et al (2016). Conceptual convergence: increased inflammation is associated with increased basal ganglia glutamate in patients with major depression. Mol Psychiatry (in press).

Haroon E, Raison CL, Miller AH (2012). Psychoneuroimmunology meets neuropsychopharmacology: translational implications of the impact of inflammation on behavior. Neuropsychopharmacology 37: 137-162.

Harrison NA, Cercignani M, Voon V, Critchley HD (2015a). Effects of inflammation on hippocampus and substantia nigra responses to novelty in healthy human participants. Neuropsychopharmacology 40: 831-838.

Harrison NA, Voon V, Cercignani M, Cooper EA, Pessiglione M, Critchley HD (2015b). A neurocomputational account of how inflammation enhances sensitivity to punishments versus rewards. Biol Psychiatry 80: 73-81.

Hartmann MN, Hager OM, Reimann AV, Chumbley JR, Kirschner M, Seifritz E et al (2015). Apathy but not diminished expression in schizophrenia is associated with discounting of monetary rewards by physical effort. Schizophr Bull 41: 503-512.

Haruki H, Hovius R, Pedersen MG, Johnsson K (2016). Tetrahydrobiopterin biosynthesis as a potential target of the kynurenine pathway metabolite xanthurenic acid. J Biol Chem 291: 652-657. 
Hashimoto R, Nagatsu T, Ohta T, Mizutani M, Omura I (2004). Changes in the concentrations of tetrahydrobiopterin, the cofactor of tyrosine hydroxylase, in blood under physical stress and in depression. Ann NY Acad Sci 1018: 378-386.

Hasler G, Fromm S, Carlson PJ, Luckenbaugh DA, Waldeck T, Geraci M et al (2008). Neural response to catecholamine depletion in unmedicated subjects with major depressive disorder in remission and healthy subjects. Arch Gen Psychiatry 65: $521-531$

Heinz A, Knable MB, Coppola R, Gorey JG, Jones DW, Lee KS et al (1998). Psychomotor slowing, negative symptoms and dopamine receptor availability-an IBZM SPECT study in neuroleptic-treated and drug-free schizophrenic patients. Schizophr Res 31: 19-26.

Hershenberg R, Satterthwaite TD, Daldal A, Katchmar N, Moore TM, Kable JW et al (2016). Diminished effort on a progressive ratio task in both unipolar and bipolar depression. J Affect Disord 196: 97-100.

Hirvonen J, Karlsson H, Kajander J, Markkula J, Rasi-Hakala H, Nagren K et al (2008). Striatal dopamine D2 receptors in medication-naive patients with major depressive disorder as assessed with [11C]raclopride PET. Psychopharmacology (Berl) 197: 581-590.

Ho BT, Huo YY, Lu JG, Tansey LW, Levin VA (1992). Opioid-dopaminergic mechanisms in the potentiation of $d$-amphetamine discrimination by interferonalpha. Pharmacol Biochem Behav 42: 57-60.

Hodes GE, Pfau ML, Leboeuf M, Golden SA, Christoffel DJ, Bregman D et al (2014). Individual differences in the peripheral immune system promote resilience versus susceptibility to social stress. Proc Natl Acad Sci USA 111: 16136-16141.

Horan WP, Reddy LF, Barch DM, Buchanan RW, Dunayevich E, Gold JM et al (2015). Effort-based decision-making paradigms for clinical trials in schizophrenia: part 2-external validity and correlates. Schizophr Bull 41: 1055-1065.

Howe MW, Tierney PL, Sandberg SG, Phillips PE, Graybiel AM (2013). Prolonged dopamine signalling in striatum signals proximity and value of distant rewards. Nature 500: 575-579.

Howren MB, Lamkin DM, Suls J (2009). Associations of depression with C-reactive protein, IL-1, and IL-6: a meta-analysis. Psychosom Med 71: 171-186.

Hufner K, Oberguggenberger A, Kohl C, Geisler S, Gamper E, Meraner V et al (2015). Levels in neurotransmitter precursor amino acids correlate with mental health in patients with breast cancer. Psychoneuroendocrinology 60: 28-38.

Imaizumi M, Kim HJ, Zoghbi SS, Briard E, Hong J, Musachio JL et al (2007). PET imaging with [11C]PBR28 can localize and quantify upregulated peripheral benzodiazepine receptors associated with cerebral ischemia in rat. Neurosci Lett 411: 200-205.

Inagaki TK, Muscatell KA, Irwin MR, Moieni M, Dutcher JM, Jevtic I et al (2015). The role of the ventral striatum in inflammatory-induced approach toward support figures. Brain Behav Immun 44: 247-252.

Iravani MM, Sadeghian M, Leung CC, Tel BC, Rose S, Schapira AH et al (2008). Continuous subcutaneous infusion of pramipexole protects against lipopolysaccharide-induced dopaminergic cell death without affecting the inflammatory response. Exp Neurol 212: 522-531.

Jamal O, Aneni EC, Shaharyar S, Ali SS, Parris D, McEvoy JW et al (2014). Cigarette smoking worsens systemic inflammation in persons with metabolic syndrome. Diabetol Metabo Syndr 6: 79-86.

Jang SW, Liu X, Yepes M, Shepherd KR, Miller GW, Liu Y et al (2010). A selective TrkB agonist with potent neurotrophic activities by 7,8-dihydroxyflavone. Proc Natl Acad Sci USA 107: 2687-2692.

Jayaram-Lindstrom N, Wennberg P, Hurd YL, Franck J (2004). Effects of naltrexone on the subjective response to amphetamine in healthy volunteers. J Clin Psychopharmacol 24: 665-669.

Juengling FD, Ebert D, Gut O, Engelbrecht MA, Rasenack J, Nitzsche EU et al (2000). Prefrontal cortical hypometabolism during low-dose interferon alpha treatment. Psychopharmacology (Berl) 152: 383-389.

Kaasinen V, Nurmi E, Bruck A, Eskola O, Bergman J, Solin O et al (2001). Increased frontal [(18)Fffluorodopa uptake in early Parkinson's disease: sex differences in the prefrontal cortex. Brain 124(Pt 6): 1125-1130.

Kaiser RH, Andrews-Hanna JR, Wager TD, Pizzagalli DA (2015). Large-scale network dysfunction in major depressive disorder: a meta-analysis of resting-state functional connectivity. JAMA Psychiatry 72: 603-611.

Kamata M, Higuchi H, Yoshimoto M, Yoshida K, Shimizu T (2000). Effect of single intracerebroventricular injection of alpha-interferon on monoamine concentrations in the rat brain. Eur Neuropsychopharmacol 10: 129-132.

Katsuura G, Arimura A, Koves K, Gottschall PE (1990). Involvement of organum vasculosum of lamina terminalis and preoptic area in interleukin 1 beta-induced ACTH release. Am J Physiol 258(1 Pt 1): E163-E171.

Kazumori H, Ishihara S, Rumi MA, Ortega-Cava CF, Kadowaki Y, Kinoshita Y (2004). Transforming growth factor-alpha directly augments histidine decarboxylase and vesicular monoamine transporter 2 production in rat enterochromaffin-like cells. Am J Physiol Gastrointest Liver Physiol 286: G508-G514.
Keedwell PA, Andrew C, Williams SC, Brammer MJ, Phillips ML (2005). A double dissociation of ventromedial prefrontal cortical responses to sad and happy stimuli in depressed and healthy individuals. Biol Psychiatry 58: 495-503.

Kenk M, Selvanathan T, Rao N, Suridjan I, Rusjan P, Remington G et al (2015). Imaging neuroinflammation in gray and white matter in schizophrenia: an in vivo PET study with [18F]-FEPPA. Schizophr Bull 41: 85-93.

Khaodhiar L, Ling PR, Blackburn GL, Bistrian BR (2004). Serum levels of interleukin6 and C-reactive protein correlate with body mass index across the broad range of obesity. JPEN J Parenter Enteral Nutr 28: 410-415.

Kitagami T, Yamada K, Miura H, Hashimoto R, Nabeshima T, Ohta T (2003). Mechanism of systemically injected interferon-alpha impeding monoamine biosynthesis in rats: role of nitric oxide as a signal crossing the blood-brain barrier. Brain Res 978: 104-114.

Klimke A, Larisch R, Janz A, Vosberg H, Muller-Gartner HW, Gaebel W (1999). Dopamine D2 receptor binding before and after treatment of major depression measured by [123|]IBZM SPECT. Psychiatry Res 90: 91-101.

Knutson B, Gibbs SE (2007). Linking nucleus accumbens dopamine and blood oxygenation. Psychopharmacology 191: 813-822.

Köhler O, Benros ME, Nordentoft M, Farkouh ME, lyengar RL, Mors O et al (2014). Effect of anti-inflammatory treatment on depression, depressive symptoms, and adverse effects: a systematic review and meta-analysis of randomized clinical trials. JAMA Psychiatry 71: 1381-1391.

Kosel M, Bilkei-Gorzo A, Zawatzky R, Zimmer A, Schlaepfer TE (2011). Pegylated human interferon alpha 2 a does not induce depression-associated changes in mice. Psychiatry Res 185: 243-247.

Kring AM, Gur RE, Blanchard JJ, Horan WP, Reise SP (2013). The clinical assessment interview for negative symptoms (CAINS): final development and validation. Am J Psychiatry 170: 165-172.

Kumai T, Tateishi T, Tanaka M, Watanabe M, Shimizu H, Kobayashi S (2000). Effect of interferon-alpha on tyrosine hydroxylase and catecholamine levels in the brain of rats. Life Sci 67: 663-669.

Kumakura Y, Cumming P (2009). PET studies of cerebral levodopa metabolism: a review of clinical findings and modeling approaches. Neuroscientist 15: 635-650.

Kumakura Y, Gjedde A, Danielsen EH, Christensen S, Cumming P (2006). Dopamine storage capacity in caudate and putamen of patients with early Parkinson's disease: correlation with asymmetry of motor symptoms. J Cereb Blood Flow Metab 26: 358-370.

Kumar AM, Ownby RL, Waldrop-Valverde D, Fernandez B, Kumar M (2011). Human immunodeficiency virus infection in the CNS and decreased dopamine availability: relationship with neuropsychological performance. J Neurovirol 17: 26-40.

Lammel S, Ion DI, Roeper J, Malenka RC (2011). Projection-specific modulation of dopamine neuron synapses by aversive and rewarding stimuli. Neuron 70 : 855-862.

Lammel S, Lim BK, Ran C, Huang KW, Betley MJ, Tye KM et al (2012). Inputspecific control of reward and aversion in the ventral tegmental area. Nature 491: $212-217$

Lanquillon S, Krieg JC, Bening-Abu-Shach U, Vedder H (2000). Cytokine production and treatment response in major depressive disorder. Neuropsychopharmacology 22: 370-379.

Lavicky J, Dunn AJ (1993). Corticotropin-releasing factor stimulates catecholamine release in hypothalamus and prefrontal cortex in freely moving rats as assessed by microdialysis. J Neurochem 60: 602-612.

Le Masurier M, Houston G, Cowen P, Grasby P, Sharp T, Hume S (2004). Tyrosinefree amino acid mixture attenuates amphetamine-induced displacement of [11C] raclopride in striatum in vivo: a rat PET study. Synapse 51: 151-157.

Lebena A, Vegas O, Gomez-Lazaro E, Arregi A, Garmendia L, Beitia G et al (2014). Melanoma tumors alter proinflammatory cytokine production and monoamine brain function, and induce depressive-like behavior in male mice. Behav Brain Res 272: 83-92.

Leenders KL, Palmer AJ, Quinn N, Clark JC, Firnau G, Garnett ES et al (1986). Brain dopamine metabolism in patients with Parkinson's disease measured with positron emission tomography. J Neurol Neurosurg Psychiatry 49: 853-860.

Leentjens AF, Van den Akker M, Metsemakers JF, Lousberg R, Verhey FR (2003). Higher incidence of depression preceding the onset of Parkinson's disease: a register study. Mov Disord 18: 414-418.

Lemke MR, Puhl P, Koethe N, Winkler T (1999). Psychomotor retardation and anhedonia in depression. Acta Psychiatr Scand 99: 252-256.

Levine J, Barak Y, Chengappa KN, Rapoport A, Rebey M, Barak V (1999). Cerebrospinal cytokine levels in patients with acute depression. Neuropsychobiology 40: 171-176.

Leyton M, Dagher A, Boileau I, Casey K, Baker GB, Diksic M et al (2004). Decreasing amphetamine-induced dopamine release by acute phenylalanine/tyrosine depletion: A PET/[11C]raclopride study in healthy men. Neuropsychopharmacology 29: $427-432$ 
Li W, Knowlton D, Woodward WR, Habecker BA (2003). Regulation of noradrenergic function by inflammatory cytokines and depolarization. J Neurochem 86: 774-783.

Liggins J, Pihl RO, Benkelfat C, Leyton M (2012). The dopamine augmenter L-DOPA does not affect positive mood in healthy human volunteers. PLOS ONE 7: e28370.

Lim W, Hong S, Nelesen R, Dimsdale JE (2005). The association of obesity, cytokine levels, and depressive symptoms with diverse measures of fatigue in healthy subjects. Arch Intern Med 165: 910-915.

Lindqvist D, Janelidze S, Hagell P, Erhardt S, Samuelsson M, Minthon L et al (2009). Interleukin-6 is elevated in the cerebrospinal fluid of suicide attempters and related to symptom severity. Biol Psychiatry 66: 287-292.

Lockhart A, Davis B, Matthews JC, Rahmoune H, Hong G, Gee A et al (2003). The peripheral benzodiazepine receptor ligand PK11195 binds with high affinity to the acute phase reactant $\alpha 1$-acid glycoprotein: implications for the use of the ligand as a CNS inflammatory marker. Nucl Med Biol 30: 199-206.

Loftis JM, Hauser P, Macey TA, Lowe JD (2006a). Can rodents be used to model interferon-alpha-induced depressive symptoms? Prog Neuropsychopharmacol Biol Psychiatry 30: 1364-1365.

Loftis JM, Wall JM, Pagel RL, Hauser P (2006b). Administration of pegylated interferon-alpha-2a or $-2 \mathrm{~b}$ does not induce sickness behavior in Lewis rats. Psychoneuroendocrinology 31: 1289-1294.

Lotharius J, Falsig J, van Beek J, Payne S, Dringen R, Brundin P et al (2005). Progressive degeneration of human mesencephalic neuron-derived cells triggered by dopamine-dependent oxidative stress is dependent on the mixed-lineage kinase pathway. J Neurosci 25: 6329-6342.

Maes M (1999). Major depression and activation of the inflammatory response system. Adv Exp Med Biol 461: 25-46.

Maes M, Lambrechts J, Bosmans E, Jacobs J, Suy E, Vandervorst C et al (1992). Evidencess for a systemic immune activation during depression: results of leukocyte enumeration by flow cytometry in conjunction with monoclonal antibody staining. Psychol Med 22: 45-53.

Majer M, Welberg LA, Capuron L, Pagnoni G, Raison CL, Miller AH (2008). IFN-alpha-induced motor slowing is associated with increased depression and fatigue in patients with chronic hepatitis C. Brain Behav Immun 22: 870-880.

Makino M, Kitano Y, Komiyama C, Hirohashi M, Kohno M, Moriyama M et al (2000a). Human interferon-alpha induces immobility in the mouse forced swimming test: involvement of the opioid system. Brain Res 852: 482-484.

Makino M, Kitano Y, Komiyama C, Takasuna K (2000b). Human interferon-alpha increases immobility in the forced swimming test in rats. Psychopharmacology (Berl) 148: 106-110

Mar Fan HG, Clemons M, Xu W, Chemerynsky I, Breunis H, Braganza S et al (2008). A randomised, placebo-controlled, double-blind trial of the effects of d-methylphenidate on fatigue and cognitive dysfunction in women undergoing adjuvant chemotherapy for breast cancer. Support Care Cancer 16: 577-583.

Marshall SA, McClain JA, Kelso ML, Hopkins DM, Pauly JR, Nixon K (2013). Microglial activation is not equivalent to neuroinflammation in alcohol-induced neurodegeneration: The importance of microglia phenotype. Neurobiol Dis 54: 239-251.

Martinez JM, Garakani A, Yehuda R, Gorman JM (2012). Proinflammatory and "resiliency" proteins in the CSF of patients with major depression. Depress Anxiety 29: 32-38.

Martinot M, Bragulat V, Artiges E, Dolle F, Hinnen F, Jouvent R et al (2001). Decreased presynaptic dopamine function in the left caudate of depressed patients with affective flattening and psychomotor retardation. Am J Psychiatry 158: 314-316.

Masilamoni GJ, Bogenpohl JW, Alagille D, Delevich K, Tamagnan G, Votaw JR et al (2011). Metabotropic glutamate receptor 5 antagonist protects dopaminergic and noradrenergic neurons from degeneration in MPTP-treated monkeys. Brain 134 (Pt 7): 2057-2073.

Matsuzaki I, Takamatsu Y, Moroji T (1989). The effects of intracerebroventricularly injected corticotropin-releasing factor (CRF) on the central nervous system: behavioural and biochemical studies. Neuropeptides 13: 147-155.

McCarthy JM, Treadway MT, Bennett ME, Blanchard JJ (2016). Inefficient effort allocation and negative symptoms in individuals with schizophrenia. Schizophr Res 170: 278-284

McKinney WT Jr., Eising RG, Moran EC, Suomi SJ, Harlow HF (1971). Effects of reserpine on the social behavior of rhesus monkeys. Dis Nerv Syst 32: 735-741.

McLean A, Rubinsztein JS, Robbins TW, Sahakian BJ (2004). The effects of tyrosine depletion in normal healthy volunteers: implications for unipolar depression. Psychopharmacology 171: 286-297.

Meier-Ewert HK, Ridker PM, Rifai N, Regan MM, Price NJ, Dinges DF et al (2004). Effect of sleep loss on C-reactive protein, an inflammatory marker of cardiovascular risk. J Am Coll Cardiol 43: 678-683.
Meisner F, Scheller C, Kneitz S, Sopper S, Neuen-Jacob E, Riederer P et al (2008). Memantine upregulates BDNF and prevents dopamine deficits in SIV-infected macaques: a novel pharmacological action of memantine. Neuropsychopharmacology 33: 2228-2236.

Mekaouche M, Siaud P, Givalois L, Barbanel G, Malaval F, Maurel D et al (1996). Different responses of plasma $\mathrm{ACTH}$ and corticosterone and of plasma interleukin-1 beta to single and recurrent endotoxin challenges. J Leukoc Biol 5 9: $341-346$.

Mentis MJ, Mclntosh AR, Perrine K, Dhawan V, Berlin B, Feigin A et al (2002). Relationships among the metabolic patterns that correlate with mnemonic, visuospatial, and mood symptoms in Parkinson's disease. Am J Psychiatry 159: $746-754$

Michaelides M, Thanos PK, Kim R, Cho J, Ananth M, Wang GJ et al (2012). PET imaging predicts future body weight and cocaine preference. Neuroimage 59: $1508-1513$

Michopoulos V, Rothbaum AO, Jovanovic T, Almli LM, Bradley B, Rothbaum BO et al (2015). Association of CRP genetic variation and CRP level with elevated PTSD symptoms and physiological responses in a civilian population with high levels of trauma. Am J Psychiatry 172: 353-362.

Miller AH, Ancoli-Israel S, Bower JE, Capuron L, Irwin MR (2008). Neuroendocrineimmune mechanisms of behavioral comorbidities in patients with cancer. J Clin Oncol 26: 971-982.

Miller AH, Jones JF, Drake DF, Tian H, Unger ER, Pagnoni G (2014). Decreased basal ganglia activation in subjects with chronic fatigue syndrome: association with symptoms of fatigue. PLoS One 9: e98156.

Miller AH, Raison CL (2015). Are anti-inflammatory therapies viable treatments for psychiatric disorders? where the rubber meets the road. JAMA Psychiatry 72 527-528.

Miller BJ, Buckley P, Seabolt W, Mellor A, Kirkpatrick B (2011). Meta-analysis of cytokine alterations in schizophrenia: clinical status and antipsychotic effects. Biol Psychiatry 70: 663-671.

Miller GE, Cole SW (2012). Clustering of depression and inflammation in adolescents previously exposed to childhood adversity. Biol Psychiatry 72: 34-40.

Miller GE, Freedland KE, Carney RM, Stetler CA, Banks WA (2003). Pathways linking depression, adiposity, and inflammatory markers in healthy young adults. Brain Behav Immun 17: 276-285.

Miller GE, Stetler CA, Carney RM, Freedland KE, Banks WA (2002). Clinical depression and inflammatory risk markers for coronary heart disease. Am J Cardiol 90: 1279-1283.

Mitchell PB, Wilhelm K, Parker G, Austin MP, Rutgers P, Malhi GS (2001). The clinical features of bipolar depression: a comparison with matched major depressive disorder patients. J Clin Psychiatry 62: 212-216.

Mitterschiffthaler MT, Kumari V, Malhi GS, Brown RG, Giampietro VP, Brammer MJ et al (2003). Neural response to pleasant stimuli in anhedonia: an fMRI study. Neuroreport 14: 177-182.

Moraska AR, Sood A, Dakhil SR, Sloan JA, Barton D, Atherton PJ et al (2010). Phase III, randomized, double-blind, placebo-controlled study of long-acting methylphenidate for cancer-related fatigue: North Central Cancer Treatment Group NCCTG-N05C7 trial. J Clin Oncol 28: 3673-3679.

Moron JA, Zakharova I, Ferrer JV, Merrill GA, Hope B, Lafer EM et al (2003). Mitogen-activated protein kinase regulates dopamine transporter surface expression and dopamine transport capacity. J Neurosci 23: 8480-8488.

Morrens M, Hulstijn W, Sabbe B (2007). Psychomotor slowing in schizophrenia. Schizophr Bull 33: 1038-1053.

Morris RW, Vercammen A, Lenroot R, Moore L, Langton JM, Short B et al (2011). Disambiguating ventral striatum fMRI-related bold signal during reward prediction in schizophrenia. Mol Psychiatry 17: 280-289.

Morrow GR, Hickok JT, Roscoe JA, Raubertas RF, Andrews PL, Flynn PJ et al (2003). Differential effects of paroxetine on fatigue and depression: a randomized, double-blind trial from the University of Rochester Cancer Center Community Clinical Oncology Program. J Clin Oncol 21: 4635-4641.

Mostafavi S, Battle A, Zhu X, Potash JB, Weissman MM, Shi J et al (2014). Type I interferon signaling genes in recurrent major depression: increased expression detected by whole-blood RNA sequencing. Mol Psychiatry 19: 1267-1274.

Motivala SJ, Sarfatti A, Olmos L, Irwin MR (2005). Inflammatory markers and sleep disturbance in major depression. Psychosom Med 67: 187-194.

Muscatell KA, Moieni M, Inagaki TK, Dutcher JM, Jevtic I, Breen EC et al (2016). Exposure to an inflammatory challenge enhances neural sensitivity to negative and positive social feedback. Brain Behav Immun (in press).

Musselman DL, Lawson DH, Gumnick JF, Manatunga AK, Penna S, Goodkin RS et al (2001). Paroxetine for the prevention of depression induced by high-dose interferon alfa. N Engl J Med 344: 961-966.

Najjar S, Pearlman DM, Devinsky O, Najjar A, Zagzag D (2013). Neurovascular unit dysfunction with blood-brain barrier hyperpermeability contributes to major 
depressive disorder: a review of clinical and experimental evidence. J Neuroinflammation 10: 142.

Neurauter G, Schrocksnadel K, Scholl-Burgi S, Sperner-Unterweger B, Schubert C, Ledochowski $\mathrm{M}$ et al (2008). Chronic immune stimulation correlates with reduced phenylalanine turnover. Curr Drug Metab 9: 622-627.

Nierenberg AA (2015). Residual symptoms in depression: prevalence and impact. J Clin Psychiatry 76: e1480.

Niv Y, Daw ND, Joel D, Dayan P (2007). Tonic dopamine: opportunity costs and the control of response vigor. Psychopharmacology 191: 507-520.

Nunes EJ, Randall PA, Estrada A, Epling B, Hart EE, Lee CA et al (2014). Effortrelated motivational effects of the pro-inflammatory cytokine interleukin 1-beta: studies with the concurrent fixed ratio 5/ chow feeding choice task. Psychopharmacology (Berl) 231: 727-736.

Nunes EJ, Randall PA, Hart EE, Freeland C, Yohn SE, Baqi Y et al (2013). Effortrelated motivational effects of the VMAT-2 inhibitor tetrabenazine: implications for animal models of the motivational symptoms of depression. J Neurosci 33: 19120-19130.

Nusslock R, Miller GE (2015). Early-life adversity and physical and emotional health across the lifespan: a neuroimmune network hypothesis. Biol Psychiatry 80: 23-32.

Nutt D, Demyttenaere K, Janka Z, Aarre T, Bourin M, Canonico PL et al (2007). The other face of depression, reduced positive affect: the role of catecholamines in causation and cure. J Psychopharmacol 21: 461-471.

O'Connor JC, Lawson MA, Andre C, Briley EM, Szegedi SS, Lestage J et al (2009a). Induction of IDO by bacille Calmette-Guerin is responsible for development of murine depressive-like behavior. J Immunol 182: 3202-3212.

O'Connor JC, Lawson MA, Andre C, Moreau M, Lestage J, Castanon N et al (2008). Lipopolysaccharide-induced depressive-like behavior is mediated by indoleamine 2,3-dioxygenase activation in mice. Mol Psychiatry 14: 511-522.

O'Connor JC, Lawson MA, Andre C, Moreau M, Lestage J, Castanon N et al (2009b). Lipopolysaccharide-induced depressive-like behavior is mediated by indoleamine 2,3-dioxygenase activation in mice. Mol Psychiatry 14: 511-522.

O'Doherty J, Dayan P, Schultz J, Deichmann R, Friston K, Dolan RJ (2004). Dissociable roles of ventral and dorsal striatum in instrumental conditioning. Science 304: 452-454.

Opp MR, Born J, Irwin MR (2007). Sleep and the immune systemln:Ader R (ed). Psychoneuroimmunology. Academic Press: New York, NY, USA. pp 570-618.

Orsal AS, Blois SM, Bermpohl D, Schaefer M, Coquery N (2008). Administration of interferon-alpha in mice provokes peripheral and central modulation of immune cells, accompanied by behavioral effects. Neuropsychobiology 58: 211-222.

Oya K, Kishi T, Iwata N (2014). Efficacy and tolerability of minocycline augmentation therapy in schizophrenia: a systematic review and meta-analysis of randomized controlled trials. Hum Psychopharmacol 29: 483-491.

Pace TW, Mletzko TC, Alagbe O, Musselman DL, Nemeroff CB, Miller AH et al (2006). Increased stress-induced inflammatory responses in male patients with major depression and increased early life stress. Am J Psychiatry 163: 1630-1633.

Pacheco R, Contreras F, Zouali M (2014). The dopaminergic system in autoimmune diseases. Front Immunol 5: 117.

Pan L, McKain BW, Madan-Khetarpal S, McGuire M, Diler RS, Perel JM et al (2011). GTP-cyclohydrolase deficiency responsive to sapropterin and 5-HTP supplementation: relief of treatment-refractory depression and suicidal behaviour. BMJ Case Rep 2011: 1-3.

Pan W, Kastin AJ (2003). Interactions of cytokines with the blood-brain barrier: implications for feeding. Curr Pharm Des 9: 827-831.

Papakostas GI, Mischoulon D, Shyu I, Alpert JE, Fava M (2010). S-adenosyl methionine (SAMe) augmentation of serotonin reuptake inhibitors for antidepressant nonresponders with major depressive disorder: a double-blind, randomized clinical trial. Am J Psychiatry 167: 942-948.

Papakostas Gl, Petersen T, Mischoulon D, Green CH, Nierenberg AA, Bottiglieri T et al (2004a). Serum folate, vitamin B12, and homocysteine in major depressive disorder, Part 2: predictors of relapse during the continuation phase of pharmacotherapy. J Clin Psychiatry 65: 1096-1098.

Papakostas Gl, Petersen T, Mischoulon D, Ryan JL, Nierenberg AA, Bottiglieri T et al (2004b). Serum folate, vitamin B12, and homocysteine in major depressive disorder, Part 1: predictors of clinical response in fluoxetine-resistant depression. J Clin Psychiatry 65: 1090-1095.

Papakostas Gl, Shelton RC, Zajecka JM, Etemad B, Rickels K, Clain A et al (2012). L-methylfolate as adjunctive therapy for SSRI-resistant major depression: results of two randomized, double-blind, parallel-sequential trials. Am J Psychiatry 169: 1267-1274.

Park HS, Park JY, Yu R (2005). Relationship of obesity and visceral adiposity with serum concentrations of CRP, TNF-alpha and IL-6. Diabetes Res Clin Pract 69: 29-35.
Parker G, Fink M, Shorter E, Taylor MA, Akiskal H, Berrios G et al (2010). Issues for DSM-5: whither melancholia? The case for its classification as a distinct mood disorder. Am J Psychiatry 167: 745-747.

Parsey RV, Oquendo MA, Zea-Ponce Y, Rodenhiser J, Kegeles LS, Pratap M et al (2001). Dopamine D(2) receptor availability and amphetamine-induced dopamine release in unipolar depression. Biol Psychiatry 50: 313-322.

Pessiglione M, Seymour B, Flandin G, Dolan RJ, Frith CD (2006). Dopaminedependent prediction errors underpin reward-seeking behaviour in humans. Nature 442: 1042-1045.

Phillips PE, Walton ME, Jhou TC (2007). Calculating utility: preclinical evidence for cost-benefit analysis by mesolimbic dopamine. Psychopharmacology (Berl) 191: 483-495.

Pizzagalli DA (2014). Depression, stress, and anhedonia: toward a synthesis and integrated model. Annu Rev Clin Psychol 10: 393-423.

Pizzagalli DA, Holmes AJ, Dillon DG, Goetz EL, Birk JL, Bogdan R et al (2009). Reduced caudate and nucleus accumbens response to rewards in unmedicated individuals with major depressive disorder. Am J Psychiatry 166: 702-710.

Pizzagalli DA, losifescu D, Hallett LA, Ratner KG, Fava M (2008). Reduced hedonic capacity in major depressive disorder: evidence from a probabilistic reward task. J Psychiatr Res 43: 76-87.

Pollak Y, Yirmiya R (2002). Cytokine-induced changes in mood and behaviour: implications for 'depression due to a general medical condition', immunotherapy and antidepressive treatment. Int J Neuropsychopharmaco/ 5: 389-399.

Potvin S, Stip E, Sepehry AA, Gendron A, Bah R, Kouassi E (2008). Inflammatory cytokine alterations in schizophrenia: a systematic quantitative review. Biol Psychiatry 63: 801-808.

Price RB, Nock MK, Charney DS, Mathew SJ (2009). Effects of intravenous ketamine on explicit and implicit measures of suicidality in treatment-resistant depression. Biol Psychiatry 66: 522-526.

Pucci E, Branas P, D'Amico R, Giuliani G, Solari A, Taus C (2007). Amantadine for fatigue in multiple sclerosis. Cochrane Database Syst Rev: CD002818.

Puryear CB, Kim MJ, Mizumori SJ (2010). Conjunctive encoding of movement and reward by ventral tegmental area neurons in the freely navigating rodent. Behav Neurosci 124: 234-247.

Qin L, Wu X, Block ML, Liu Y, Breese GR, Hong JS et al (2007). Systemic LPS causes chronic neuroinflammation and progressive neurodegeneration. Glia 55 : 453-462.

Radua J, Schmidt A, Borgwardt S, Heinz A, Schlagenhauf F, McGuire P et al (2015). Ventral striatal activation during reward processing in psychosis: a neurofunctional meta-analysis. JAMA psychiatry 72: 1243-1251.

Raison CL, Borisov AS, Broadwell SD, Capuron L, Woolwine BJ, Jacobson IM et al (2005a). Depression during pegylated interferon-alpha plus ribavirin therapy: prevalence and prediction. J Clin Psychiatry 66: 41-48.

Raison CL, Borisov AS, Majer M, Drake DF, Pagnoni G, Woolwine BJ et al (2009). Activation of central nervous system inflammatory pathways by interferon-alpha: relationship to monoamines and depression. Biol Psychiatry 65: 296-303.

Raison CL, Dantzer R, Kelley KW, Lawson MA, Woolwine BJ, Vogt G et al (2010a). CSF concentrations of brain tryptophan and kynurenines during immune stimulation with IFN-alpha: relationship to CNS immune responses and depression. Mol Psychiatry 15: 393-403.

Raison CL, Demetrashvili M, Capuron L, Miller AH (2005b). Neuropsychiatric adverse effects of interferon-alpha: recognition and management. CNS Drugs 19: 105-123.

Raison CL, Felger JC, Miller AH (2013a). Inflammation and treatment resistance in major depression: a perfect storm. Psychiatric Times. 12 September.

Raison CL, Miller AH (2003). Depression in cancer: new developments regarding diagnosis and treatment. Biol Psychiatry 54: 283-294.

Raison CL, Miller AH (2011). Is depression an inflammatory disorder? Curr Psychiatry Rep 13: 467-475.

Raison CL, Miller AH (2013). The evolutionary significance of depression in Pathogen Host Defense (PATHOS-D). Mol Psychiatry 18: 15-37.

Raison CL, Rutherford RE, Woolwine BJ, Shuo C, Schettler P, Drake DF et al (2013b). A randomized controlled trial of the tumor necrosis factor antagonist infliximab for treatment-resistant depression: the role of baseline inflammatory biomarkers. JAMA Psychiatry 70: 31-41.

Raison CL, Rye DB, Woolwine BJ, Vogt GJ, Bautista BM, Spivey JR et al (2010b). Chronic interferon-alpha administration disrupts sleep continuity and depth in patients with hepatitis C: association with fatigue, motor slowing, and increased evening cortisol. Biol Psychiatry 68: 942-949.

Raivich G, Bohatschek M, Kloss CU, Werner A, Jones LL, Kreutzberg GW (1999). Neuroglial activation repertoire in the injured brain: graded response, molecular mechanisms and cues to physiological function. Brain Res Rev 30: 77-105.

Randall PA, Lee CA, Podurgiel SJ, Hart E, Yohn SE, Jones M et al (2015). Bupropion increases selection of high effort activity in rats tested on a progressive ratio/chow 
feeding choice procedure: implications for treatment of effort-related motivational symptoms. Int J Neuropsychopharmacol 18: 1-11.

Rapaport MH, Nierenberg AA, Schettler PJ, Kinkead B, Cardoos A, Walker R et al (2016). Inflammation as a predictive biomarker for response to omega-3 fatty acids in major depressive disorder: a proof-of-concept study. Mol Psychiatry 21: $71-79$.

Reddy LF, Horan WP, Barch DM, Buchanan RW, Dunayevich E, Gold JM et al (2015). Effort-based decision-making paradigms for clinical trials in schizophrenia: part 1-psychometric characteristics of 5 paradigms. Schizophr Bull 41: 1045-1054.

Reinert KR, Umphlet CD, Quattlebaum A, Boger HA (2014). Short-term effects of an endotoxin on substantia nigra dopamine neurons. Brain Res 1557: 164-170.

Reuter J, Raedler T, Rose M, Hand I, Glascher J, Buchel C (2005). Pathological gambling is linked to reduced activation of the mesolimbic reward system. Nat Neurosci 8: 147-148.

Reynolds JN, Hyland BI, Wickens JR (2001). A cellular mechanism of reward-related learning. Nature 413: $67-70$.

Ridker PM (2003). Clinical application of C-reactive protein for cardiovascular disease detection and prevention. Circulation 107: 363-369.

Romo R, Schultz W (1990). Dopamine neurons of the monkey midbrain: contingencies of responses to active touch during self-initiated arm movements. J Neurophysiol 63: 592-606.

Rosenblat JD, Kakar R, Berk M, Kessing LV, Vinberg M, Baune BT et al (2016). Antiinflammatory agents in the treatment of bipolar depression: a systematic review and meta-analysis. Bipolar Disord 18: 89-101.

Rosenzweig-Lipson S, Hesterberg P, Bergman J (1994). Observational studies of dopamine D1 and D2 agonists in squirrel monkeys. Psychopharmacology (Berl) 116: 9-18.

Ruddy KJ, Barton D, Loprinzi CL (2014). Laying to rest psychostimulants for cancerrelated fatigue? J Clin Oncol 32: 1865-1867.

Rush AJ (2007). STAR*D: what have we learned? Am J Psychiatry 164: 201-204.

Russo SJ, Nestler EJ (2013). The brain reward circuitry in mood disorders. Nat Rev Neurosci 14: 609-625.

Rutledge RB, Dean M, Caplin A, Glimcher PW (2010). Testing the reward prediction error hypothesis with an axiomatic model. J Neurosci 30: 13525-13536.

Saijo K, Glass CK (2011). Microglial cell origin and phenotypes in health and disease. Nat Rev Immunol 11: 775-787.

Salamone JD, Correa M (2012). The mysterious motivational functions of mesolimbic dopamine. Neuron 76: 470-485.

Salamone JD, Cousins MS, Snyder BJ (1997). Behavioral functions of nucleus accumbens dopamine: empirical and conceptual problems with the anhedonia hypothesis. Neurosci Biobehav Rev 21: 341-359.

Salamone JD, Wisniecki A, Carlson BB, Correa M (2001). Nucleus accumbens dopamine depletions make animals highly sensitive to high fixed ratio requirements but do not impair primary food reinforcement. Neuroscience 105: 863-870.

Samanez-Larkin GR, Knutson B (2015). Decision making in the ageing brain: changes in affective and motivational circuits. Nat Rev Neurosci 16: 278-289.

Sandiego CM, Gallezot J-D, Pittman B, Nabulsi N, Lim K, Lin S-F et al (2015). Imaging robust microglial activation after lipopolysaccharide administration in humans with PET. Proc Natl Acad Sci USA 112: 12468-12473.

Santamaria A, Flores-Escartin A, Martinez JC, Osorio L, Galvan-Arzate S, PedrazaChaverri J et al (2003). Copper blocks quinolinic acid neurotoxicity in rats: contribution of antioxidant systems. Free Radic Biol Med 35: 418-427.

Sarris J, Papakostas Gl, Vitolo O, Fava M, Mischoulon D (2014). S-adenosyl methionine (SAMe) versus escitalopram and placebo in major depression RCT: efficacy and effects of histamine and carnitine as moderators of response. J Affect Disord 164: 76-81.

Sarris J, Price LH, Carpenter LL, Tyrka AR, Ng CH, Papakostas Gl et al (2015). Is S-adenosyl methionine (SAMe) for depression only effective in males? A re-analysis of data from a randomized clinical trial. Pharmacopsychiatry 48: 141-144.

Sato $H$, Uematsu M, Endo W, Nakayama T, Kobayashi T, Hino-Fukuyo $N$ et al (2014). Early replacement therapy in a first Japanese case with autosomal recessive guanosine triphosphate cyclohydrolase I deficiency with a novel point mutation. Brain Dev 36: 268-271.

Sato T, Suzuki E, Yokoyama M, Semba J, Watanabe S, Miyaoka H (2006). Chronic intraperitoneal injection of interferon-alpha reduces serotonin levels in various regions of rat brain, but does not change levels of serotonin transporter mRNA, nitrite or nitrate. Psychiatry Clin Neurosci 60: 499-506.

Scheller C, Sopper S, Jenuwein M, Neuen-Jacob E, Tatschner T, Grunblatt E et al (2005). Early impairment in dopaminergic neurotransmission in brains of SIVinfected rhesus monkeys due to microglia activation. J Neurochem 95: 377-387.

Schizophrenia Working Group of the Psychiatric Genomics C (2014). Biological insights from 108 schizophrenia-associated genetic loci. Nature 511: 421-427.
Schönberg T, Daw ND, Joel D, O'Doherty JP (2007). Reinforcement learning signals in the human striatum distinguish learners from nonlearners during reward-based decision making. J Neurosci 27: 12860-12867.

Schultz W (2002). Getting formal with dopamine and reward. Neuron 36: 241-263.

Schultz W (2015). Neuronal reward and decision signals: from theories to data. Physiol Rev 95: 853-951.

Schwarcz R, Pellicciari R (2002). Manipulation of brain kynurenines: glial targets, neuronal effects, and clinical opportunities. J Pharmacol Exp Ther 303: 1-10.

Schwieler L, Larsson MK, Skogh E, Kegel ME, Orhan F, Abdelmoaty S et al (2015). Increased levels of IL-6 in the cerebrospinal fluid of patients with chronic schizophrenia-significance for activation of the kynurenine pathway. J Psychiatry Neurosci 40: 126-133.

Setiawan E, Wilson AA, Mizrahi R, Rusjan PM, Miler L, Rajkowska G et al (2015). Role of translocator protein density, a marker of neuroinflammation, in the brain during major depressive episodes. JAMA Psychiatry 72: 268-275.

Shah PJ, Ogilvie AD, Goodwin GM, Ebmeier KP (1997). Clinical and psychometric correlates of dopamine D2 binding in depression. Psychol Med 27: 1247-1256.

Shao W, Zhang SZ, Tang M, Zhang XH, Zhou Z, Yin YQ et al (2013). Suppression of neuroinflammation by astrocytic dopamine D2 receptors via alphaB-crystallin. Nature 494: 90-94.

Sharot T, Guitart-Masip M, Korn CW, Chowdhury R, Dolan RJ (2012). How dopamine enhances an optimism bias in humans. Curr Biol 22: 1477-1481.

Sharot T, Shiner T, Brown AC, Fan J, Dolan RJ (2009). Dopamine enhances expectation of pleasure in humans. Curr Biol 19: 2077-2080.

Shelton RC, Claiborne J, Sidoryk-Wegrzynowicz M, Reddy R, Aschner M, Lewis DA et al (2011). Altered expression of genes involved in inflammation and apoptosis in frontal cortex in major depression. Mol Psychiatry 16: 751-762.

Shelton RC, Miller AH (2010). Eating ourselves to death (and despair): the contribution of adiposity and inflammation to depression. Prog Neurobio/ 91 275-299.

Shelton RC, Pencina MJ, Barrentine LW, Ruiz JA, Fava M, Zajecka JM et al (2015). Association of obesity and inflammatory marker levels on treatment outcome: results from a double-blind, randomized study of adjunctive L-methylfolate calcium in patients with MDD who are inadequate responders to SSRIs. J Clin Psychiatry 76: 1635-1641.

Shelton RC, Tomarken AJ (2001). Can recovery from depression be achieved? Psychiatr Serv 52: 1469-1478.

Shintaku H (2002). Disorders of tetrahydrobiopterin metabolism and their treatment. Curr Drug Metab 3: 123-131.

Shuto H, Kataoka Y, Horikawa T, Fujihara N, Oishi R (1997). Repeated interferonalpha administration inhibits dopaminergic neural activity in the mouse brain. Brain Res 747: 348-351.

Sissolak G, Hoffbrand AV, Mehta AB, Ganeshaguru K (1992). Effects of interferonalpha (IFN) on the expression of interleukin 1-beta (IL-1), interleukin 6 (IL-6), granulocyte-macrophage colony-stimulating factor (GM-CSF) and tumor necrosis factor-alpha (TNF) in acute myeloid leukemia (AML) blasts. Leukemia 6: 1155-1160

Sluzewska A (1999). Indicators of immune activation in depressed patients. Adv Exp Med Biol 461: 59-73.

Sluzewska A, Sobieska M, Rybakowski JK (1997). Changes in acute-phase proteins during lithium potentiation of antidepressants in refractory depression. Neuropsychobiology 35: 123-127.

Soderlund J, Olsson SK, Samuelsson M, Walther-Jallow L, Johansson C, Erhardt S et al (2011). Elevation of cerebrospinal fluid interleukin-1ss in bipolar disorder. J Psychiatry Neurosci 36: 114-118.

Soderlund J, Schroder J, Nordin C, Samuelsson M, Walther-Jallow L, Karlsson H et al (2009). Activation of brain interleukin-1beta in schizophrenia. Mol Psychiatry 14: 1069-1071.

Sommer IE, de Witte L, Begemann M, Kahn RS (2012). Nonsteroidal antiinflammatory drugs in schizophrenia: ready for practice or a good start? A metaanalysis. J Clin Psychiatry 734: 414-419.

Spetsieris PG, Moeller JR, Dhawan V, Ishikawa T, Eidelberg D (1995). Visualizing the evolution of abnormal metabolic networks in the brain using PET. Comput Med Imaging Graph 19: 295-306.

Stahl SM (2007). Novel therapeutics for depression: L-methylfolate as a trimonoamine modulator and antidepressant-augmenting agent. CNS Spectr 12 739-744.

Stankoff B, Waubant E, Confavreux C, Edan G, Debouverie M, Rumbach L et al (2005). Modafinil for fatigue in MS: a randomized placebo-controlled doubleblind study. Neurology 64: 1139-1143.

Steele KE, Prokopowicz GP, Schweitzer MA, Magunsuon TH, Lidor AO, Kuwabawa $\mathrm{H}$ et al (2010). Alterations of central dopamine receptors before and after gastric bypass surgery. Obes Surg 20: 369-374.

Stein DJ (2008). Depression, anhedonia, and psychomotor symptoms: the role of dopaminergic neurocircuitry. CNS Spectr 13: 561-565. 
Steiner J, Walter M, Gos T, Guillemin GJ, Bernstein HG, Sarnyai Z et al (2011). Severe depression is associated with increased microglial quinolinic acid in subregions of the anterior cingulate gyrus: evidence for an immune-modulated glutamatergic neurotransmission? J Neuroinflammation 8: 94.

Strauss GP, Gold JM (2012). A New Perspective on Anhedonia in Schizophrenia. Am J Psychiatry 169: 364-373.

Strauss GP, Whearty KM, Morra LF, Sullivan SK, Ossenfort KL, Frost KH (2016). Avolition in schizophrenia is associated with reduced willingness to expend effort for reward on a Progressive Ratio task. Schizophr Res 170: 198-204.

Stringaris A, Vidal-Ribas Belil P, Artiges E, Lemaitre H, Gollier-Briant F, Wolke S et al (2015). The brain's response to reward anticipation and depression in adolescence: dimensionality, specificity, and longitudinal predictions in a community-based sample. Am J Psychiatry 172: 1215-1223.

Suarez EC (2008). Self-reported symptoms of sleep disturbance and inflammation, coagulation, insulin resistance and psychosocial distress: evidence for gender disparity. Brain Behav Immun 22: 960-968.

Suganami T, Ogawa Y (2010). Adipose tissue macrophages: their role in adipose tissue remodeling. J Leukoc Biol 88: 33-39.

Sugawara Y, Akechi T, Shima Y, Okuyama T, Akizuki N, Nakano T et al (2002). Efficacy of methylphenidate for fatigue in advanced cancer patients: a preliminary study. Palliat Med 16: 261-263.

Surguladze S, Brammer MJ, Keedwell P, Giampietro V, Young AW, Travis MJ et al (2005). A differential pattern of neural response toward sad versus happy facial expressions in major depressive disorder. Biol Psychiatry 57: 201-209.

Syed EC, Grima LL, Magill PJ, Bogacz R, Brown P, Walton ME (2016). Action initiation shapes mesolimbic dopamine encoding of future rewards. Nat Neurosci 19: 34-36.

Takaki J, Fujimori K, Miura M, Suzuki T, Sekino Y, Sato K (2012). L-glutamate released from activated microglia downregulates astrocytic L-glutamate transporter expression in neuroinflammation: the 'collusion' hypothesis for increased extracellular L-glutamate concentration in neuroinflammation. I Neuroinflammation 9: 275.

Targum SD, Fava M (2011). Fatigue as a residual symptom of depression. Innov Clin Neurosci 8: 40-43.

Tavares RG, Schmidt AP, Abud J, Tasca Cl, Souza DO (2005). In vivo quinolinic acid increases synaptosomal glutamate release in rats: reversal by guanosine. Neurochem Res 30: 439-444.

Tavares RG, Tasca Cl, Santos CES, Alves LB, Porciuncula LO, Emanuelli T et al (2002). Quinolinic acid stimulates synaptosomal glutamate release and inhibits glutamate uptake into astrocytes. Neurochem Int 40: 621-627.

Taylor JL, Grossberg SE (1998). The effects of interferon-alpha on the production and action of other cytokines. Semin Oncol 25(1 Suppl 1): 23-29.

Tian $Y Y$, An LJ, Jiang L, Duan YL, Chen J, Jiang B (2006). Catalpol protects dopaminergic neurons from LPS-induced neurotoxicity in mesencephalic neuronglia cultures. Life Sci 80: 193-199.

Tilleux S, Hermans E (2007). Neuroinflammation and regulation of glial glutamate uptake in neurological disorders. J Neurosci Res 85: 2059-2070.

Timpson NJ, Nordestgaard BG, Harbord RM, Zacho J, Frayling TM, TybjaergHansen A et al (2011). C-reactive protein levels and body mass index: elucidating direction of causation through reciprocal Mendelian randomization. Int $J$ Obes (Lond) 35: 300-308.

Torres-Platas SG, Cruceanu C, Chen GG, Turecki G, Mechawar N (2014). Evidence for increased microglial priming and macrophage recruitment in the dorsal anterior cingulate white matter of depressed suicides. Brain Behav Immun 42: 50-59.

Treadway MT, Bossaller NA, Shelton RC, Zald DH (2012a). Effort-based decisionmaking in major depressive disorder: a translational model of motivational anhedonia. J Abnorm Psychol 121: 553.

Treadway MT, Buckholtz JW, Cowan RL, Woodward ND, Li R, Ansari MS et al (2012b). Dopaminergic mechanisms of individual differences in human effortbased decision-making. J Neurosci 32: 6170-6176.

Treadway MT, Buckholtz JW, Schwartzman AN, Lambert WE, Zald DH (2009). Worth the 'EEfRT'? The effort expenditure for rewards task as an objective measure of motivation and anhedonia. PLoS One 4: e6598.

Treadway MT, Pizzagalli DA (2014). Imaging the pathophysiology of major depressive disorder - from localist models to circuit-based analysis. Biol Mood Anxiety Disord 4: 5.

Treadway MT, Zald DH (2011). Reconsidering anhedonia in depression: lessons from translational neuroscience. Neurosci Biobehav Rev 35: 537-555.

Treadway MT, Zald DH (2013). Parsing anhedonia translational models of rewardprocessing deficits in psychopathology. Curr Dir Psychol Sci 22: 244-249.

Trefz FK, Burton BK, Longo N, Casanova MM, Gruskin DJ, Dorenbaum A et al (2009). Efficacy of sapropterin dihydrochloride in increasing phenylalanine tolerance in children with phenylketonuria: a phase III, randomized, double-blind, placebo-controlled study. J Pediatr 154: 700-707.
Tremblay LK, Naranjo CA, Cardenas L, Herrmann N, Busto UE (2002). Probing brain reward system function in major depressive disorder: altered response to dextroamphetamine. Arch Gen Psychiatry 59: 409-416.

Tremblay LK, Naranjo CA, Graham SJ, Herrmann N, Mayberg HS, Hevenor S et al (2005). Functional neuroanatomical substrates of altered reward processing in major depressive disorder revealed by a dopaminergic probe. Arch Gen Psychiatry 62: 1228-1236.

Tremblay ME, Stevens B, Sierra A, Wake H, Bessis A, Nimmerjahn A (2011). The role of microglia in the healthy brain. J Neurosci 31: 16064-16069.

Trivedi MH, Hollander E, Nutt D, Blier P (2008). Clinical evidence and potential neurobiological underpinnings of unresolved symptoms of depression. J Clin Psychiatry 69: 246-258.

Uomoto M, Nishibori M, Nakaya N, Takeuchi Y, Iwagaki H, Tanaka N et al (1998). Changes in monoamine turnover in the brain of cachectic mice bearing colon-26 tumor cells. J Neurochem 70: 260-267.

Utz JR, Lorentz CP, Markowitz D, Rudser KD, Diethelm-Okita B, Erickson D et al (2012). START, a double blind, placebo-controlled pharmacogenetic test of responsiveness to sapropterin dihydrochloride in phenylketonuria patients. Mol Genet Metab 105: 193-197.

van Heesch F, Prins J, Konsman JP, Korte-Bouws GA, Westphal KG, Rybka J et al (2014). Lipopolysaccharide increases degradation of central monoamines: an in vivo microdialysis study in the nucleus accumbens and medial prefrontal cortex of mice. Eur J Pharmacol 725: 55-63.

van Heesch F, Prins J, Konsman JP, Westphal KG, Olivier B, Kraneveld AD et al (2013). Lipopolysaccharide-induced anhedonia is abolished in male serotonin transporter knockout rats: an intracranial self-stimulation study. Brain Behav Immun 29: 98-103.

Varazzani C, San-Galli A, Gilardeau S, Bouret S (2015). Noradrenaline and dopamine neurons in the reward/effort trade-off: a direct electrophysiological comparison in behaving monkeys. J Neurosci 35: 7866-7877.

Venneti S, Lopresti BJ, Wang G, Slagel SL, Mason NS, Mathis CA et al (2007). A comparison of the high-affinity peripheral benzodiazepine receptor ligands DAA1106 and (R)-PK11195 in rat models of neuroinflammation: implications for PET imaging of microglial activation. J Neurochem 102: 2118-2131.

Venugopalan W, Casey KF, O'Hara C, O'Loughlin J, Benkelfat C, Fellows LK et al (2011). Acute phenylalanine/tyrosine depletion reduces motivation to smoke cigarettes across stages of addiction. Neuropsychopharmacology 36: 2469-2476.

Vgontzas AN, Papanicolaou DA, Bixler EO, Lotsikas A, Zachman K, Kales A et al (1999). Circadian interleukin-6 secretion and quantity and depth of sleep. $J$ Clin Endocrinol Metab 84: 2603-2607.

Vgontzas AN, Zoumakis E, Bixler EO, Lin HM, Follett H, Kales A et al (2004). Adverse effects of modest sleep restriction on sleepiness, performance, and inflammatory cytokines. J Clin Endocrinol Metab 89: 2119-2126.

Vichaya EG, Hunt SC, Dantzer R (2014). Lipopolysaccharide reduces incentive motivation while boosting preference for high reward in mice. Neuropsychopharmacology 39: 2884-2890.

Voon V, Morris LS, Irvine MA, Ruck C, Worbe Y, Derbyshire K et al (2015). Risktaking in disorders of natural and drug rewards: neural correlates and effects of probability, valence, and magnitude. Neuropsychopharmacology 40: 804-812.

Walter U, Heilmann R, Kaulitz L, Just T, Krause BJ, Benecke R et al (2015). Prediction of Parkinson's disease subsequent to severe depression: a ten-year follow-up study. J Neural Transm (Vienna) 122: 789-797.

Wang J, Campbell IL, Zhang H (2008). Systemic interferon-alpha regulates interferon-stimulated genes in the central nervous system. Mol Psychiatry 13: 293-301.

Wang JY, Zeng XY, Fan GX, Yuan YK, Tang JS (2006). mu- but not delta- and kappa-opioid receptor mediates the nucleus submedius interferon-alpha-evoked antinociception in the rat. Neurosci Lett 397: 254-258.

Wardle MC, Treadway MT, Mayo LM, Zald DH, de Wit H (2011). Amping up effort: effects of d-amphetamine on human effort-based decision-making. J Neurosci 31: 16597-16602.

Watkins LR, Goehler LE, Relton JK, Tartaglia N, Silbert L, Martin D et al (1995). Blockade of interleukin-1 induced hyperthermia by subdiaphragmatic vagotomy: evidence for vagal mediation of immune-brain communication. Neurosci Lett 183: 27-31.

Watkins LR, Wiertelak EP, Goehler LE, Mooney-Heiberger K, Martinez J, Furness L et al (1994). Neurocircuitry of illness-induced hyperalgesia. Brain Res 639: 283-299.

Weisberg SP, McCann D, Desai M, Rosenbaum M, Leibel RL, Ferrante AW Jr. (2003). Obesity is associated with macrophage accumulation in adipose tissue. $J$ Clin Invest 112: 1796-1808.

Wichmann T, DeLong MR (1999). Oscillations in the basal ganglia. Nature 400: $621-622$. 
Wichmann T, DeLong MR (2003). Functional neuroanatomy of the basal ganglia in Parkinson's disease. Adv Neurol 91: 9-18.

Williams LE, Blackford JU, Luksik A, Gauthier I, Heckers S (2013). Reduced habituation in patients with schizophrenia. Schizophr Res 151: 124-132.

Wilson AA, Garcia A, Parkes J, McCormick P, Stephenson KA, Houle S et al (2008). Radiosynthesis and initial evaluation of [18 F]-FEPPA for PET imaging of peripheral benzodiazepine receptors. Nucl Med Biol 35: 305-314.

Winton-Brown TT, Fusar-Poli P, Ungless MA, Howes OD (2014). Dopaminergic basis of salience dysregulation in psychosis. Trends Neurosci 37: 85-94.

Wohleb ES, Fenn AM, Pacenta AM, Powell ND, Sheridan JF, Godbout JP (2012). Peripheral innate immune challenge exaggerated microglia activation, increased the number of inflammatory CNS macrophages, and prolonged social withdrawal in socially defeated mice. Psychoneuroendocrinology 37: 1491-1505.

Wohleb ES, McKim DB, Shea DT, Powell ND, Tarr AJ, Sheridan JF et al (2014). Reestablishment of anxiety in stress-sensitized mice is caused by monocyte trafficking from the spleen to the brain. Biol Psychiatry 75: 970-981.

Wolf DH, Satterthwaite TD, Kantrowitz JJ, Katchmar N, Vandekar L, Elliott MA et al (2014). Amotivation in schizophrenia: integrated assessment with behavioral, clinical, and imaging measures. Schizophr Bull 40: 1328-1337.

Xia Y, Tsai AL, Berka V, Zweier JL (1998). Superoxide generation from endothelial nitric-oxide synthase. A Ca2+/calmodulin-dependent and tetrahydrobiopterin regulatory process. J Biol Chem 273: 25804-25808.

Xie X, Mhaskar Y, Arbogast LA, Trammell RA, Hughes LF, Toth LA (2009). Adenosine receptor antagonists and behavioral activation in NF-kappaB p50 subunit knockout mice. Life Sci 85: 226-234.

Yang JJ, Wang N, Yang C, Shi JY, Yu HY, Hashimoto K (2015). Serum interleukin-6 is a predictive biomarker for ketamine's antidepressant effect in treatmentresistant patients with major depression. Biol Psychiatry 77: e19-e20.

Yang X-h, Huang J, Zhu C-y, Wang Y-f, Cheung EFC, Chan RCK et al (2014). Motivational deficits in effort-based decision making in individuals with subsyndromal depression, first-episode and remitted depression patients. Psychiatry Res 220: 874-882.

Yeh KY, Shou SS, Lin YX, Chen CC, Chiang CY, Yeh CY (2015). Effect of Ginkgo biloba extract on lipopolysaccharide-induced anhedonic depressive-like behavior in male rats. Phytother Res 29: 260-266.
Yirmiya R, Pollak Y, Morag M, Reichenberg A, Barak O, Avitsur R et al (2000). Illness, cytokines, and depression. Ann NY Acad Sci 917: 478-487.

Yirmiya R, Weidenfeld J, Pollak Y, Morag M, Morag A, Avitsur R et al (1999). Cytokines, "depression due to a general medical condition," and antidepressant drugs. Adv Exp Med Biol 461: 283-316.

Yohn SE, Lopez-Cruz L, Hutson PH, Correa M, Salamone JD (2016). Effects of lisdexamfetamine and s-citalopram, alone and in combination, on effort-related choice behavior in the rat. Psychopharmacology (Berl) 233: 949-960.

Yohn SE, Thompson C, Randall PA, Lee CA, Muller CE, Baqi Y et al (2015). The VMAT-2 inhibitor tetrabenazine alters effort-related decision making as measured by the T-maze barrier choice task: reversal with the adenosine A2A antagonist MSX-3 and the catecholamine uptake blocker bupropion. Psychopharmacology (Berl) 232: 1313-1323.

Yokoyama K, Tajima M, Yoshida H, Nakayama M, Tokutome G, Sakagami H et al (2002). Plasma pteridine concentrations in patients with chronic renal failure. Nephrol Dial Transplant 17: 1032-1036.

Zaghloul KA, Blanco JA, Weidemann CT, McGill K, Jaggi JL, Baltuch GH et al (2009). Human substantia nigra neurons encode unexpected financial rewards. Science 323: 1496-1499.

Zheng LS, Hitoshi S, Kaneko N, Takao K, Miyakawa T, Tanaka Y et al (2014). Mechanisms for interferon-alpha-induced depression and neural stem cell dysfunction. Stem Cell Rep 3: 73-84.

Zhu CB, Blakely RD, Hewlett WA (2006). The proinflammatory cytokines interleukin1 beta and tumor necrosis factor-alpha activate serotonin transporters. Neuropsychopharmacology 31: 2121-2131.

Zhu CB, Carneiro AM, Dostmann WR, Hewlett WA, Blakely RD (2005). p38 MAPK activation elevates serotonin transport activity via a trafficking-independent, protein phosphatase 2A-dependent process. J Biol Chem 280: 15649-15658.

Zhu CB, Lindler KM, Owens AW, Daws LC, Blakely RD, Hewlett WA (2010). Interleukin-1 receptor activation by systemic lipopolysaccharide induces behavioral despair linked to MAPK regulation of CNS serotonin transporters. Neuropsychopharmacology 35: 2510-2520.

Zoller H, Schloegl A, Schroecksnadel S, Vogel W, Fuchs D (2012). Interferon-alpha therapy in patients with hepatitis $C$ virus infection increases plasma phenylalanine and the phenylalanine to tyrosine ratio. J Interferon Cytokine Res 32: 216-220. 